\title{
THE ARIES AURORAL MODELLING CAMPAIGN: CHARACTERIZATION AND MODELLING OF AN EVENING AURORAL ARC OBSERVED FROM A ROCKET AND A GROUND-BASED LINE OF MERIDIAN SCANNERS*
}

\author{
A. VALLANCE JONES, R. L. GATTINGER, F. CREUTZbERG, F. R. HARRIS, A. G. MeNAMARA and \\ A. W. YAU \\ Herzberg Institute of Astrophysics, National Research Council, Ottawa, Ontario, Canada K1A 0R6
}

\section{E. J. LLEWELLYN}

Institute of Space and Atmospheric Sciences, University of Saskatchewan, Saskatoon, Saskatchewan, Canada S7N OW0

D. LUMMERZHEIM $\dagger$ and $M$. H. REES

Geophysical Institute, University of Alaska, Fairbanks, AK 99775-800, U.S.A.

\section{C. MeDADE $\ddagger$}

Space Physics Research Laboratory, Department of Atmospheric, Oceanic and Space Science, University of Michigan, Ann Arbor, MI 48109, U.S.A.

and

\section{J. MARGOTŞ}

Département de Physique, Université de Montréal, Montréal, Québec, Canada H3C 3JY

\section{(Received 17 May 1991)}

\begin{abstract}
An auroral arc system excited by soft electrons was studied with a combination of in situ rocket measurements and optical tomographic techniques, using data from a photometer on a horizontal, spinning rocket and a line of three meridian scanning photometers. The ground-based scanner data at 4709, 5577, 8446 and $6300 \AA$ were successfully inverted to provide a set of volume emission rate distributions in the plane of the rocket trajectory, with a basic time resolution of $24 \mathrm{~s}$. Volume emission rate profiles, derived from these distributions peaked at about $150 \mathrm{~km}$ for 5577 and $4709 \AA$, while the $8446 \AA$ emission peaked at about $170 \mathrm{~km}$ with a more extended height distribution. The rocket photometer gave comparable volume emission rate distributions for the $3914 \AA$ emission as reported in a separate paper by McDade et al. (1991, Planet. Space Sci. 39, 895). Instruments on the rocket measured the primary electron flux during the flight and, in particular, the flux precipitating into the auroral arc overflown at apogee (McEwen et al., 1991; in preparation). The local electron density and temperature were measured by probes on the rocket (Margot and McNamara (1991; Can.J. Phys. 69, 950). The electron density measurements on the downleg were modelled using ion production rate data derived from the optical results. Model calculations of the emission height profile based on the measured electron flux agree with the observed profiles. The height distribution of the $\mathrm{N}_{2}^{+}$emission in the equatorward band, through which the rocket passed during the descent, was measured by both the rocket and the ground-based tomographic techniques and the results are in good agreement. Comparison of these profiles with model profiles indicates that the exciting primary spectrum may be represented by an accelerated Maxwellian or a Gaussian distribution centered at about $3 \mathrm{keV}$. This distribution is close to what would be obtained if the electron flux exciting the poleward form were accelerated by a $I-2 \mathrm{kV}$ upward potential drop. The relative height profiles for the volume emission rate of the $5577 \AA \mathrm{OI}$ emission and the $4709 \AA \mathrm{N}_{2}^{+}$emission were almost indistinguishable from each other for both the forms measured, with ratios in the range $38-50$; this is equivalent to $I(5577) / I(4278)$ ratios of 810. The auroral intensities and intensity ratios mcasurcd in the magnetic zenith from the ground during the period before and during the rocket flight are consistent with the primary electron fluxes and height distributions measured from the rocket. Values of $I(5577) / I(4278)$ in the range 8-10 were also measured directly by the zenith ground photometers over which the arc system passed. These values are slightly higher than those reported by Gattinger and Vallance-Jones (1972) and this may possibly indicate an enhancement of the atomic oxygen concentration at the time of the flight. Such an enhancement would be consistent with our result, that the observed values of $I(5577)$ and $I(8446)$ are also significantly higher than those modelled on the basis of the electron flux spectrum measured at apogee.
\end{abstract}

* National Research Council of Canada, paper no. 33397. $\uparrow$ Also with NCAR/HAO, P.O. Box 3000, Boulder, CO, U.S.A. $\ddagger$ Formerly also with ISAS, University of Saskatchewan, Canada. § Formerly also with HIA, NRC, Ottawa, Canada. 


\section{INTRODUCTION}

The modelling of auroral emissions involves the calculation of the evolution of a flux of down-coming primary electrons penetrating into the atmosphere. Once the height distribution of this electron flux is derived, the volume emission rate of various auroral features may be calculated for possible direct and indirect excitation processes, provided sufficient information on excitation cross sections and reaction rates is available.

Methods of testing excitation models include comparison with observed optical emissions as well as with in situ measurements of the electron flux and electron and ion concentrations. Other important quantities such as the electron and ion temperature may be derived from the models and compared with measured values. The object of these studies is to identify the important excitation processes and to understand fully other processes in the auroral ionosphere.

Four main methods of comparison between theory and observation may be distinguished and are listed below. In many cases, more than one of these tests have been applied to the same set of observations.

(1) Comparison of height-integrated intensities of emission features with predicted values based on satellite or rocket measurements of the primary particle flux above the auroral form.

(2) Comparisons for internal consistency of models and observations, e.g. consistency between modelled or observed profiles of well understood emissions such as the $\mathbf{N}_{2}^{+}$or $\mathrm{N}_{2}$ bands with predicted profiles of less well understood emissions such as OI $5577 \AA$, OI $6300 \AA$ or bands of $\mathrm{O}_{2}$.

(3) Comparisons between model profiles based on directly observed primary electron spectra measured above auroral forms and emission profiles measured by flying a rocket through the aurora.

(4) Rocket measurement of the primary particle flux by over-flying an auroral form combined with external methods to measure the emission profiles such as ground, rocket or satellite triangulation or tomography.

One of the first detailed comparisons of the height profile of auroral emissions and a theoretical model was made by Rees et al. (1967). In that work the height profiles of the 5577,6300 and $3914 \AA$ emissions were obtained from optical photometer observations from two ground stations, one almost beneath an isolated auroral arc and the other to the south, so that the two-dimensional distribution of the volume emission rate could be derived.
Since the first rocket flight (Cummings et al., 1966) carrying particle detectors and optical photometers, there have been many attempts to make detailed comparisons between the emission profiles of auroral emissions predicted from observed particle energy spectra and observed profiles measured from the ground or from rocket or satellite-borne instruments. Donahue et al. (1968), Parkinson et al. (1970), Parkinson and Zipf (1970) and Parkinson (1971) reported and analyzed an epoch-making series of well instrumented Aerobee rocket flights which addressed the problem of the excitation mechanism of the $5577 \AA$ auroral green line. Parkinson and Zipf suggested the energy transfer process from $\mathrm{N}_{2}\left(\mathrm{~A}^{3} \Sigma_{\mathrm{u}}^{+}\right)$to atomic oxygen as the principal mechanism, but were diverted from this possibly correct explanation in part because the, then current, laboratory value for the reaction was amost an order of magnitude too low. These rocket studies called into question the apparently satisfactory excitation mechanism for the $5577 \AA$ emission derived by Rees et al. (1967), namely electron impact on atomic oxygen, supplemented by an important contribution from dissociative recombination of $\mathrm{O}_{2}^{+}$. The results of the rocket measurements seemed to show that the abundance of $\mathrm{O}_{2}^{+}$in aurora was insufficient and that the low energy electron flux was likewise too weak to excite the observed green line. Indeed by 1972 it appeared that no suggested process could explain the rocket measurements.

Feldman and Doering (1975) reported results from a further important 1972 Aerobee flight in which careful measurements of the low energy electron spectrum above $3 \mathrm{cV}$ were madc. This measurement, and an independent one by Sharp and Hays (1974), indicated that the electron flux about $5 \mathrm{eV}$ was almost an order of magnitude less than predicted by the current models. Feldman (1978) reported an analysis of the optical emission profiles obtained on the same flight, which traversed steady aurora and, like the earlier Aerobee studies, used an up-down photometer (Dick and Fastie, 1969) to eliminate the effects of residual temporal intensity variations. This analysis confirmed the dominant role of energy transfer from $O\left({ }^{1} D\right)$ to $\mathrm{O}_{2}$ in the excitation of the atmospheric $\mathrm{O}_{2}$ band and confirmed the difficulty of understanding the excitation $\mathrm{O}($ ' $\mathrm{S})$.

Rees et al. (1976) compared rocket observations of incident electron fluxes and ground-based photometer measurements of 4278 and $5577 \AA$. Good agreement was found between the Rees and Jones (1973) model for $4278 \AA$, but not for $5577 \AA$, for which the calculated value was only about one-third of that observed; the result was attributed to some lack of understanding of excitation or quenching. A com- 
parison of a coordinated satellite-rocket-ground observation by Rees et al. (1977) gave satisfactory agreement for the 5577 and $6300 \AA$ OI emissions, based on the "classical" excitation schemes, but had some difficulty with $3914 \AA$. However, a further analysis by Sharp et al. (1979) using in situ data from the rocket flight for the same coordinated observation, led to the conclusion that the $\mathrm{N}_{2}(\mathrm{~A}) / \mathrm{O}$ reaction was needed to get agreement for $5577 \AA$, and that there was a deficit in the model for $6300 \AA$. The main reason for the change between the two analyses was the use of the measured low energy electron fluxes below $10 \mathrm{eV}$ rather than the theoretically calculated values. Both the Rees and Jones model and a discrete energy loss model predicted up to $10 \times$ more flux than observed in the $1-10 \mathrm{eV}$ region. Sharp and Torr (1979) re-examined the same measurements from a different point of view and also concluded that the $\mathrm{N}_{2}(\mathrm{~A}) / \mathrm{O}$ mechanism can account for the observed excitation. A further rocket flight, giving emission profiles by passing through an auroral form, was analyzed by Deans et al. (Deans et al., 1976; Deans and Shepherd, 1978) and by Yau and Shepherd (1979). These authors also concluded that the $\mathrm{N}_{2}$ (A)/O mechanism is important and necessary.

The apparent failure of the models to predict correctly the low energy electron flux, and hence to overestimate the contribution of direct electron impact excitation, was to some extent compensated by an over-estimate of the importance of quenching of $O\left({ }^{1} S\right)$ by $O$. This error was pointed out by Slanger and Black (1981). Studies by Gattinger et al. (1985) and Gerdjikova and Shepherd (1987) show that the $\mathrm{N}_{2}$ (A)/O mechanism, combined with the revised quenching rate, can provide a satisfactory explanation of the excitation of $\mathrm{O}\left({ }^{\mathrm{I}} \mathrm{S}\right)$. The energy transfer process from $\mathrm{O}_{2}\left(\mathrm{c}^{1} \Sigma_{\mathrm{u}}^{-}\right)$proposed by Solheim and Llewellyn (1979) may, as noted by Vallance Jones et al. (1985), still be viable.

Major improvements in modelling methods have been developed over the past decade by Strickland $e t$ al. (1976) and Stamnes (1980, 1981), Applications of these methods have resulted in work on the prediction of auroral intensity profiles by Strickland et al. (1983), Daniell and Strickland (1986), Hecht et al. (1989), Rees and Lummerzheim (1989) and Lummerzheim et al. (1989). Recent work by Strickland et al. (1989) and Solomon et al. (1988) seems to show that the excitation of the $6300 \AA$ emission can be explained by the "classical" mechanisms. This implies that the apparent theoretical surplus of 5-10 eV electrons discussed above may really indicäle a deficit at higher energies.

The ARIES campaign was intended to carry out further critical tests of excitation theory by using carefully coordinated rocket and ground-based measurements. It is difficult to compare the modelled and observed profiles in a straightforward and rigorous manner, because, on the one hand, the measured particle fluxes and the optical profiles cannot usually be obtained simultaneously, and consequently time variations may cause the two not to be strictly comparable; moreover, it is not easy to make reliable simultaneous measurements of neutral atmospheric composition to use in the theoretical modelling. An important objective for ARIES was to make local measurements of atmospheric neutral composition so as to make the interpretation less dependent on neutral atmosphere models. Unfortunately experimental problems prevented reliable composition measurements. Nonetheless, the two rocket flights and the ground measurements of the campaign provide useful tests of the theory for two contrasting situations, namely aurora excited by a soft flux, producing maximum emission in a $130-150 \mathrm{~km}$ range, and a hard flux with a maximum below $100 \mathrm{~km}$. The ARIES campaign was intended to obtain comprehensive data by means of techniques (3) and (4) described above.

The first technique was the classical one in which the optical emission profile is measured by rocketborne photometers viewing upwards along the direction of the Earth's magnetic field, along which the rocket trajectory is aligned as closely as possible. The emission profiles are derived by differentiation of the total measured intensity with respect to height, while the exciting particle spectrum is measured directly by particle spectrometers carried on the rocket. Provided that the auroral emission is sufficiently stable and uniform, a theoretical profile based on the particle spectrum obtained near apogee (where it is least influenced by atmospheric absorption) can be directly compared with the height profile measured during the ascent or descent through the emitting region. In addition to the work described in the previous paragraphs, auroral height profiles have becn measured in this way by Bogdanov et al. (1981), Tarasova et al. (1981) and Yagodkina et al. (1981). In principle, direct measurements of the neutral composition, in and above the emitting region, may be made from the rocket. Time and spatial changes in auroral intensity can be corrected if the upward measured intensities are normalized to the sum of the intensities measured in the upward and downward directions (Dick and Fastie, 1969). This method can compensate for changes in particle flux, provided the energy spectrum remains constant. The ARIES-A rocket flight employed this technique and the results are reported in a separate paper. 
The second technique was foreshadowed by the ground-based triangulation study of Belon et al. (1966) and the analysis of this by Rees et al. (1967). More recently Velichko et al. (1981) have reported height profiles and two-dimensional intensity distributions for 4278,5577 and $6300 \AA$ using a chain of three ground-based meridian scanning photometers. Another interesting forerunner was the study of Evans et al. (1972), in which triangulation was attained by combining the measurements of a ground scanning photometer, a rocket photometer and the latitudinal location of an auroral form, as given by the particle measurements. As employed in the present study, this technique, in principlc, overcomes the problem of temporal variation by making continuous measurements of the emission height profiles by means of a line of meridian scanning photometers on the ground while the particle spectrum is measured from the rocket.

The ARIES-B payload was launched on February 281984 , to fly over an evening auroral arc system drifting equatorwards over the observing region. The aurora proved to be of an interesting type, excited by relatively soft electrons characterized by IBC 1-2 bands with peak emission heights in the $130-150 \mathrm{~km}$ range.

The geometry for the ARIES-B experiment is shown to scale in Fig. 1. To a good approximation, the ground photometer line and the plane in which these photometers scan is also the plane of the rocket trajectory for which the azimuth is chosen in the direction of the horizontal component of the magnetic field. Consequently measurements of the rocket instruments can be directly related to optical emissions in the plane of observation. In addition to the ground photometers, the rocket carried photometers pointing perpendicular to the spin axis, which was oriented perpendicular to the trajectory plane. Thus, the photometers obtained "meridian scan" data, from which the auroral intensity distribution in the plane of the trajectory may be derived. In the ideal case, the rocket should be flown over a simple stable arc so that the information from either the ground or rocket photometers would be sufficient to define the auroral intensity distribution. For the normal real situation, the aurora may be expected to move during the rocket flight so that the additional information from the ground photometers can be used to refine the solution for the intensity distribution to correlate with the particle measurements. This was the technique which was employed in the ARIES-B flight. The array of experiments carried was highly redundant, so that despite the failure of some instruments, the flight was highly successful in characterizing the height profile of an evening auroral arc and in comparing this profile with the predictions of an auroral excitation model.

Two types of comparison were possible. First, the primary electron spectrum measured near apogee was used to predict model profiles for the 4709 or $3914 \AA$ $\mathrm{N}_{2}^{+}$bands and the 5577 and $8446 \AA$ OI lines, which were compared with the profiles derived from the ground-based photometer line and from the rocket photometers. Secondly the electron density measured along the trajectory on the downleg, which passed through a second auroral band, was compared with models based on the in situ measurements of the $\mathrm{N}_{2}^{+}$ bands from the rocket and from the ground-based tomography.

All the experiments and results are summarized in this paper, while detailed descriptions of the particle, photometer and plasma probe measurements on the rocket are given in other referenced papers, already published, in press or in preparation. The results and tomographic analysis from the chain of ground based photometers are described in detail in this paper as well as a simple modelling approach to the derivation of height profiles.

\section{INSTRUMENTATION}

\subsection{Particle detectors}

Two electron spectrometers were provided by $\mathrm{Dr}$ D. J. McEwen of the University of Saskatchewan to measure electron fluxes. The first was a soft electron spectrometer which measured fluxes in the range $28 \mathrm{eV}$ to $22 \mathrm{keV}$ with a scan period of $302 \mathrm{~ms}$ and a resolution of 0.15 . The spectrometer viewed a $10^{\circ}$ field perpendicular to the rocket spin axis which was almost perpendicular to the terrestrial magnetic field, and consequently the instrument obtained a complete pitch angle distribution for every rocket rotation $(0.4 \mathrm{~s})$. The second instrument was a suprathermal electron analyzer which measured fluxes in the range $0.7-234 \mathrm{eV}$ in 64 steps every $0.3 \mathrm{~s}$ with a resolution of 0.05 .

Additional measurements were made with an energetic particle detector package provided by the National Research Council of Canada (NRCC). This consisted of four electrostatic analyzers measuring electron intensities at $0.10,0.47,1.7$ and $7.7 \mathrm{keV}$, a solid state particle detector which measured integrated electron flux with energy thresholds of 20 and $37 \mathrm{keV}$ and two electrostatic-analyzer spectrometers for measuring $0.06-22 \mathrm{keV}$ electron fluxes in $16 \mathrm{log}$ arithmic steps. One of these was mounted at $45^{\circ}$ and the other at $90^{\circ}$ to the rocket spin axis.

A detailed account of these instruments will appear in a forthcoming paper by McEwen et al. (1991). 


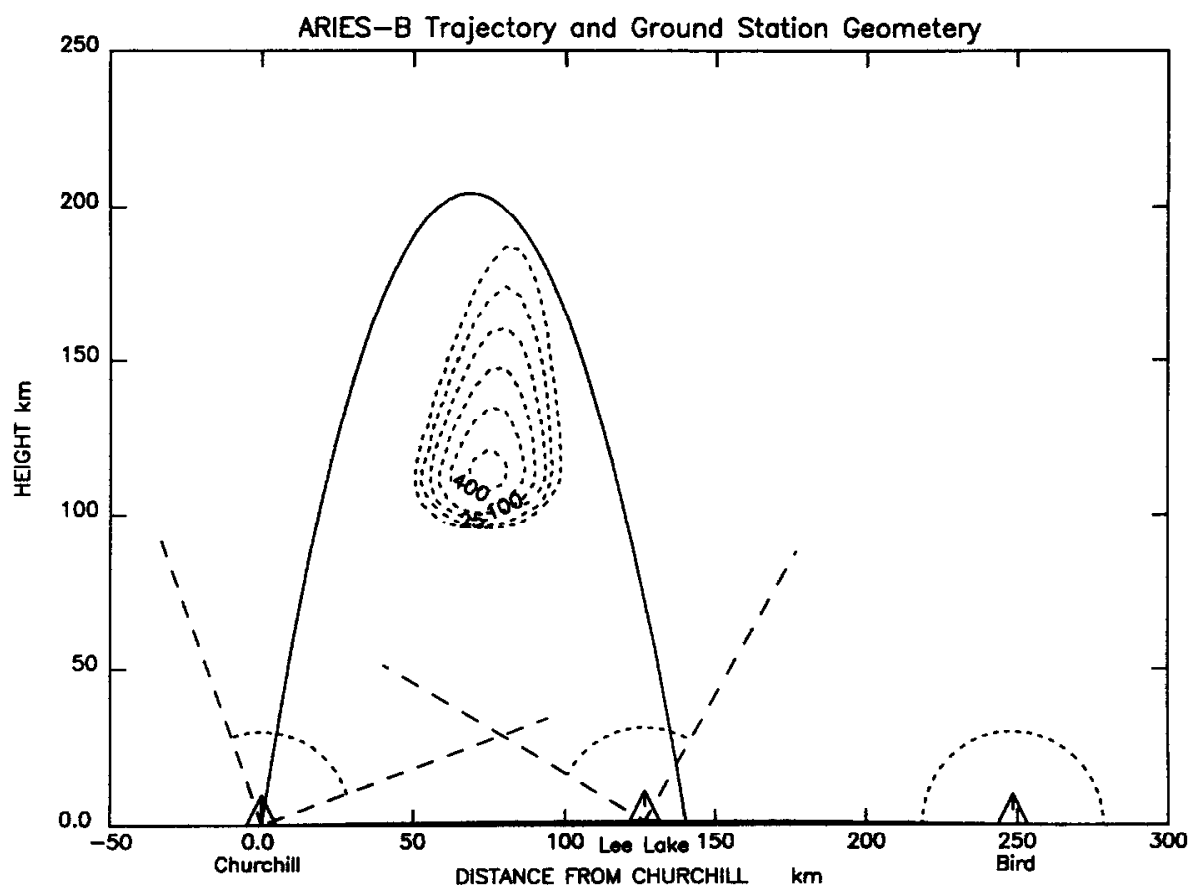

Fig. 1. SCALE DRAWING OF ROCKET, TRAJECTORY, THE GROUND STATIONS FOR THE MERIDIAN SCANNING PHOTOMETER CHAIN AND THE CONTOURS OF AN IDEALIZED AURORAL EMISSION CROSS SECTION.

The scan ranges of the ground photometers are indicated. The rocket roll axis was oriented perpendicular to the plane of the figure, so that the radially pointing rocket photometers scan continuously as the rocket rotated. As may be seen from Fig. 2, the ground stations and the rocket trajectory are very close to being co-planar.

\subsection{Rocket photometers}

Two radially pointing filter photometers were included in the payload. These were fixed photometers, designed to perform scans in the plane of the flight trajectory as a consequence of the spin of the rocket. They were of conventional design with a full field of view of $5^{\circ}$ and passbands centered at 5577 and $3914 \AA$. The filter for the $3914 \AA$ photometer had a passband (FWHM) of $50 \AA$. A full description of the $3914 \AA$ data is provided in the paper by McDade et al. (1991). The data from the $5577 \AA$ photometer suffered from some telemetry problems which have not yet been completely overcome.

\subsection{Plasma probe experiment}

Plasma density and electron temperature measurements were obtained with a spherical electrostatic probe mounted on a boom extending perpendicular to the rocket. Details of the experiment and the analysis of the current-voltage data obtained are given by Margot and McNamara (1991).

\section{4. $1^{\circ}$ Meridian scanning photometers (MSPs)}

Three identical photometers were used at the three ground stations shown in Figs 1 and 2. These instru- ments had 12-in. diameter $f / 4$ plano-convex objective lenses which focussed the sky onto a circular 0.83 in. stop, behind which a 12-channel filter wheel rotated at $20 \mathrm{~Hz}$. The filter channels and their characteristics for the three $1^{\circ}$-photometers are listed in Table 1 . The flux passing the filters was focussed on the $\mathrm{Ga}-\mathrm{As}$ cathode of a Hammamatsu R94302 photomultiplier. Pulse-counting and gating electronics were used to separate the output of the channels and the data were recorded on tape for later analysis. The light from the sky was directed into the instrument by means of a rotatable plane mirror and baffle assembly driven by a stepping motor which provided the meridian scan. Each instrument had a circular field of view with a diameter of $1.0^{\circ}$. The stepping motor was controlled by a micro-processor to provide a scan rate of about $9^{\circ} \mathrm{s}^{-1}$ so that adjacent samples were separated by $0.5^{\circ}$. The scan angle ranges of the photometers were adjustable. For the ARIES-B flight the two northern photometers were set to scan a range of $90^{\circ}$ in elevation angle and the southern one to $180^{\circ}$. In order to cover the latitude region near the rocket trajectory, the starting elevation angles (measured from the north horizon) were set at $70^{\circ}, 30^{\circ}$ and $0^{\circ}$ for the three photometers as indicated in Fig. 1. The time for each 


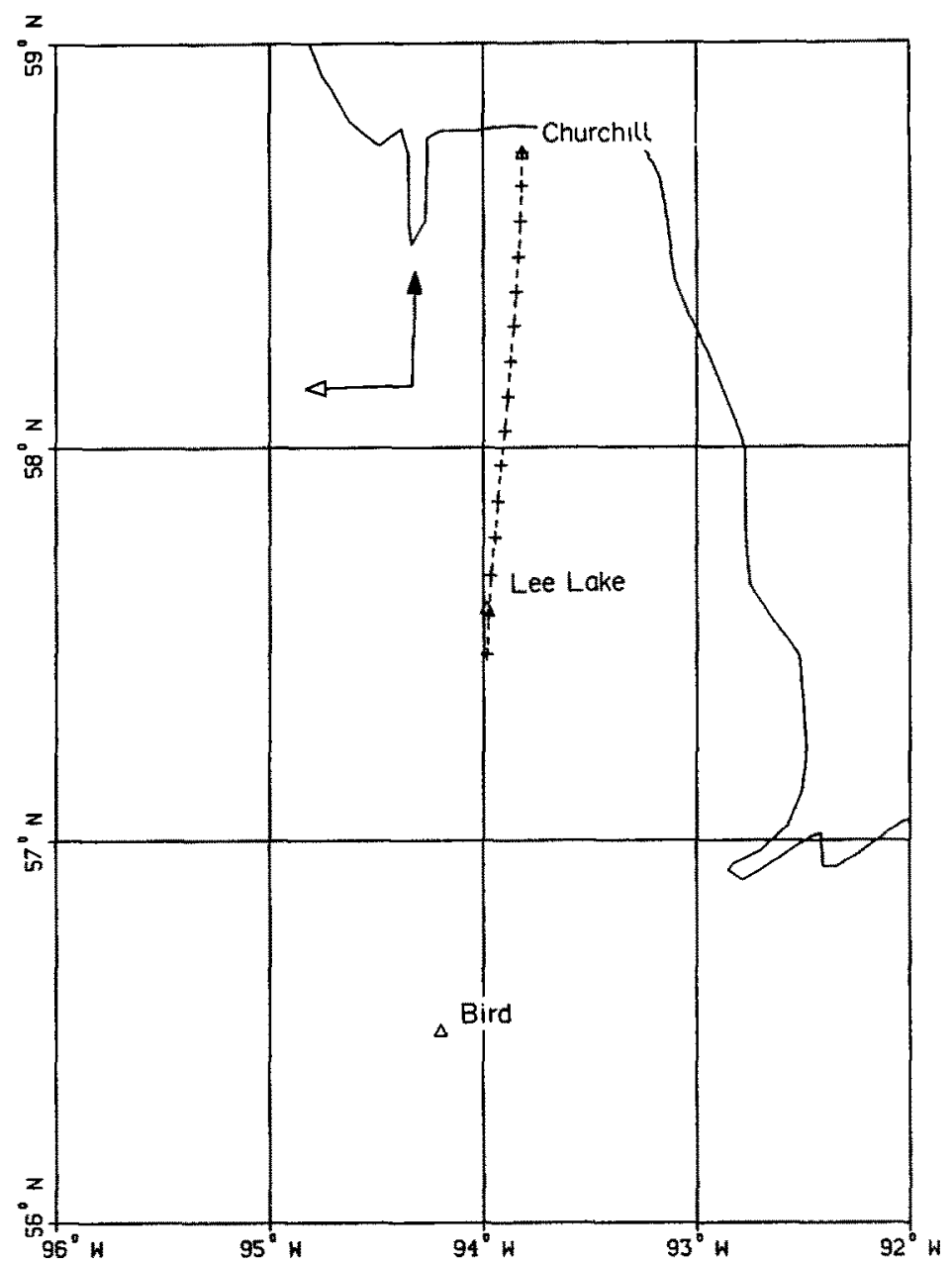

FIG. 2. MAP SHOWING PROJECTION OF ROCKET TRAIECTORY, FOOTPRINT AND LOCATION OF GROUND STATIONS. The black-headed arrow shows the direction of the horizontal component of the magnetic field at apogee and the open-headed arrow shows the direction of the roll axis of the rocket. The coordinates of the Mercator projection are geographic.

complete data cycle was $24 \mathrm{~s}$, which permitted the northern photometers to complete two scans and the southern one a single scan. The scan fly-back consumed about $17 \%$ of the observing time.

As noted above, these instruments were set out on a line along the planned rocket trajectory direction which also lay close to the local direction of the horizontal component of the terrestrial magnetic field. The geometry in the plane of the trajectory is shown in Fig. 1, while the location of the stations and trajectory are shown in the map reproduced as Fig. 2.

\subsection{Other ground-based photometers}

Also deployed at the three ground stations were the three meridian scanning photometers described by
Vallance Jones et al. (1982). These provided meridian scans on the $6300 \AA$ [OI] line and $H \beta$, as well as giving real-time scan data to help in selecting launch conditions. In addition, the 15-channel zenith photometer described by Vallance Jones et al. (1987) was set up at Churchill. A further multi-channel meridian scanner was operated at Churchill by $\mathrm{Dr} \mathrm{D}$. J. McEwen of the University of Saskatchewan.

\subsection{All-sky $T V$ system}

The ISIT all-sky TV system described by Vallance Jones and Gattinger (1981) was set up at the launch site at Fort Churchill to assist in following the development of aurora and selecting launch conditions. A second all-sky TV was provided and operated at 


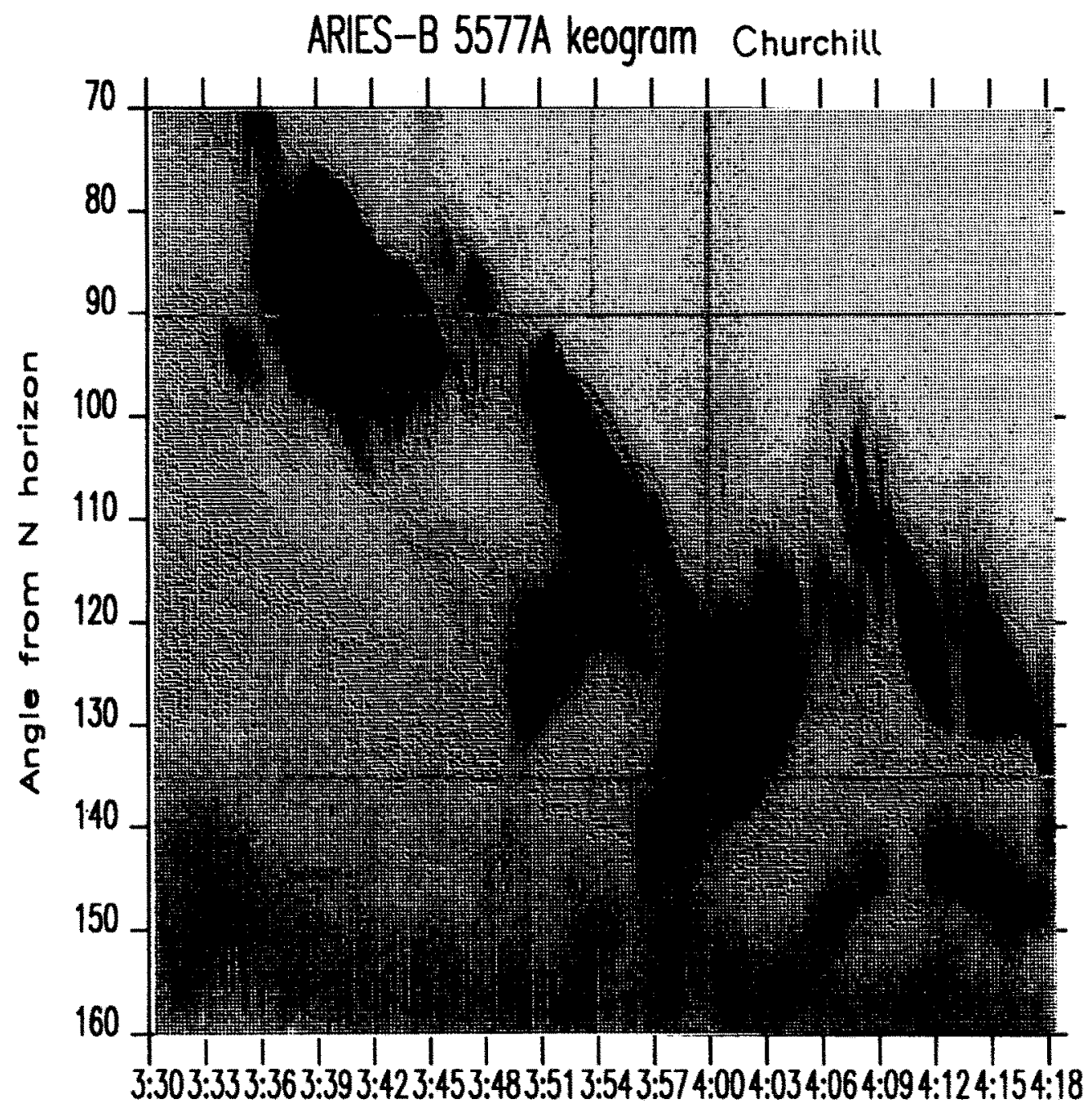

Time U.T.

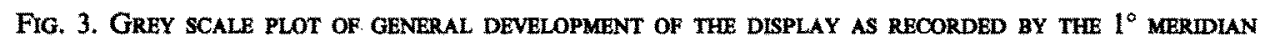
SCANNER AT FORT CHURCHLL.

The black points show the rocket footprint for a height of $150 \mathrm{~km}$. This is close to the height of maximum 5577 A emission. 

Table 1. Characteristics of pilter channels of $1^{\circ}$-Meridian sCanNERs

\begin{tabular}{llccc}
\hline Identifier & $\begin{array}{c}\text { Spectral features } \\
\text { transmitted }\end{array}$ & $\begin{array}{c}\text { Peak wavelength } \\
(\AA)\end{array}$ & $\begin{array}{c}\text { Band-pass } \\
(\AA)\end{array}$ & $\begin{array}{c}\text { Notes } \\
(2)\end{array}$ \\
\hline $4709 \AA$ & $0,2 \mathrm{~N}_{2}^{+}$IN & $4709-4710$ & $19-20$ & \\
$5275 \AA$ & $2.0 \mathrm{O}_{2}^{+} \mathrm{IN}$ & $5272-5274$ & $18-19$ & \\
$5577 \AA$ & {$[\mathrm{OI}]$} & $5577-5578$ & $15-17$ & \\
$6680 \AA$ & $5,2 \mathrm{~N}_{2}$ 1P & $6682-6690$ & $19-20$ & \\
$7690 \AA$ & $1,1 \mathrm{O}_{2}$ Atm. & $7693-7696$ & $19-21$ & \\
$7725 \AA$ & $2,0 \mathrm{~N}_{2}$ 1P & $7726-7729$ & $20-22$ & \\
$7775 \AA$ & OI & $7775-7779$ & $21-22$ & \\
$8445 \AA$ & OI & $8447-8450$ & $21-22$ & \\
$8576 \AA$ & Background & $8572-8582$ & $21-23$ & \\
$8624 \AA$ & $0,1 \mathrm{O}_{2}$ Atm. & $8526-8527$ & $22-23$ & 1 \\
$8682 \AA$ & $\mathrm{NI}$ & $8685-8687$ & $21-22$ & 1 \\
$8710 \AA$ & $2,1 \mathrm{~N}_{2}$ 1P & $8706-8709$ & $18-20$ & 1 \\
\hline
\end{tabular}

Note 1 . These features are blended together.

Note 2. The wavelength ranges given span the variations between the values for the MSPs at the three ground stations.

Churchill by Dr D. J. McEwen of the University of Sakatchewan to assist in the interpretation of the Saskatchewan meridian scanner and rocket data.

\subsection{Other experiments}

Several other experiments were flown on the rocket and in some cases produced data which, however, were not used in the analysis, either because the final data are not yet available or because of instrumental or telemetry problems. These included a two-channel auroral scanner, resonance lamps for the study of $\mathbf{N}$ and $O$ atomic concentrations, $5200 \AA, 6300 \AA, 7320$ $\AA$ and $1.27 \mu \mathrm{m}$ photometers and a polychromator to study far-UV OI and $\mathrm{N}_{2}$ LBH emissions. There was also a set of radially pointing photometers to measure $\mathrm{O}_{2}$ atmospheric bands in the $8600 \AA$ region.

\section{GEOPHYSICAL CONDITIONS AND OVER-VIEW OF OBSERVATIONS}

\subsection{Auroral conditions}

The goal for the ARIES-B flight was to fly over a stable arc so that the rocket trajectory would enclose the region of aurora, preferably with the arc conjugate to the rocket at apogee. This is difficult because more than 4 min must elapse between the decision to launch and the arrival of the rocket at apogee. A review of earlier meridian scanner records suggested that the most predictable auroral arcs are those which occur in the evening and which often move steadily equatorwards. This motion is however not always uniform and fluctuations in intensitiy do occur.

Satisfactory conditions occurred on the night of 28 February 1984. The general development of the display, as measured by the $1^{\circ}$ meridian scanner from Chur- chill is shown in Fig. 3, which covers the period from 03:30 to 04:18. (Throughout this paper all times will be given in universal time.) The general pattern is that of an arc system, drifting equatorward with an average velocity of about $100 \mathrm{~m} \mathrm{~s}^{-1}$. The figure shows that, between about 03:38, when the band was just north of the Churchill zenith, and 04:00 when it reached the Lee Lake zenith, there were intensifications centered around 03:38, 03:53 and 04:01 with weaker periods in between. At 03:50 and 03:57 additional bands appeared equatorwards of the main northern band and moved polewards to coalesce with the main band at about 03:54 and 04:00. By 03:52 the arc had reached an intensity of $8.6 \mathrm{kR}$ of $5577 \AA$ and was located about $13^{\circ}$ south of the Churchill zenith. The rocket was launched at 03:53:44.2 and reached apogee at $03: 57: 37$. The general development of the aurora is shown again in the $1^{\circ}$-meridian Churchill scanner records reproduced in Fig. 4. The rocket descended through the $100 \mathrm{~km}$ level at 04:00. As explained in the previous section, the meridian scanner viewingdircetion lies close to the rocket trajectory plane and consequently Fig. 4 gives a quantitative summary of the aurora sampled by the rocket instruments. Figure 4 shows that the main arc had increased in intensity to about $10 \mathrm{kR}$ as the rocket rose through the $118 \mathrm{~km}$ level, but then decreased in intensity to about $7 \mathrm{kR}$ by 03:55:46 when the rocket had reached $146 \mathrm{~km}$. About this time a second arc of about the same intensity is clearly visible just equatorward of the northern form. At the time of apogee the footprint of the rocket was directly over the northern arc, which had maintained its intensity. A new arc further south had replaced the earlier second form. From apogee down to $120 \mathrm{~km}$ the main arc moved equatorwards in step with the 


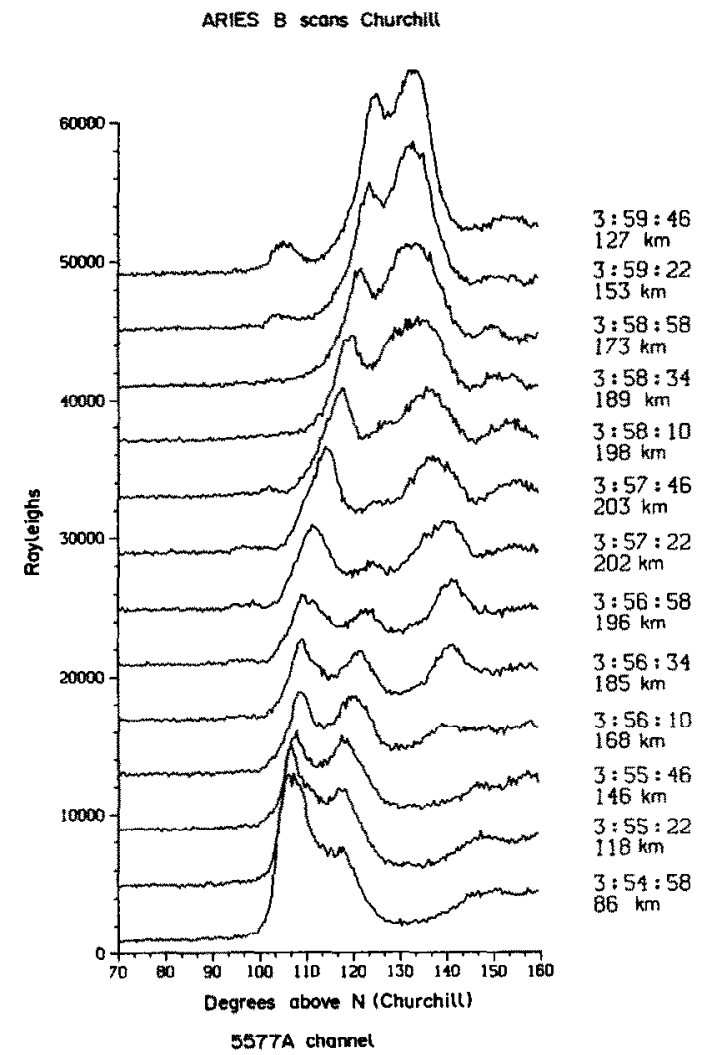

Fig. 4. MERIDIAN SCAN PLOTS FOR $5577 \AA$ INTENSITY FROM THE $1^{\circ}$ MERIDIAN SCANNER AT FORT CHURCHLL.

The mid-times and rocket height for each 24-s scan are indicated. The zero for each successive plot is displaced upward by $4000 R$.

rocket footprint while the equatorward form moved northward so that the two forms appear almost to merge into one as the rocket passed through. The intensity had increased slowly from a minimum of about $6 \mathrm{kR}$ just before apogee to about $13 \mathrm{kR}$ during the downward passage through the aurora.

A sequence of pictures obtained from the ISIT allsky TV camera, which was used both to select the desired launch conditions and to document the aurora, is reproduced in the paper by Margot and McNamara (1991). This confirms that the overall pattern of the aurora was that of a band system moving equatorward during the time of the flight.

\subsection{Rocket trajectory and manoeuvres}

The ideal geometry for the experiment, as described in the introduction, was closely approximated. The rocket trajectory is plotted on Figs 1 and 2 as described in Section 2.4 above. The location of the ground stations and the projection of the rocket tra- jectory during the flight are shown in Fig. 2. This projection lies within $1.0^{\circ}$ of the direction of the local magnetic field, of which the declination between apogee and the $100 \mathrm{~km}$ magnetic footprint of apogee was close to $1.0^{\circ}$, according to the GSFC 1980 model (Wallis, private communication). A SAAB S19 guidance system was used to ensure both the precision of flight azimuth and to satisfy safety requirements. A Space Vector attitude control system was used to orient the spin axis of the rocket into a direction perpendicular to the plane of the rocket trajectory. This manoeuver was completed at 03:55:21, at a height of $118 \mathrm{~km}$, and from that time the roll axis azimuth was close to $268.5^{\circ}$, with an elevation angle of $-2.3^{\circ}$. The direction of the magnetic field and the rocket spin axis in the horizontal plane are shown by the arrows in Fig. 2.

The planned spin period was $2 \mathrm{~s}$, but the value attained was $0.405 \mathrm{~s}$. This increased spin rate was favorable to the performance of the 5577 and $3194 \AA$ radially pointing photometers and the particle detectors. These instruments had high signal count rates and high telemetry sampling rates, and consequently the temporal resolution was improved without loss of spatial resolution.

\subsection{Particle measurements}

The NRCC and the University of Saskatchewan energetic particle detector experiments both worked well and obtained data on angular and energy distributions during the flight. The data from the NRCC fixed energy particle detectors are summarized in Fig. 5 , which shows variations with time at energies of $0.1,0.5$ and $1.7 \mathrm{keV}$. Detailed results of the particle measurements are given in the paper by McEwen et al. (1991). The electron flux spectra measured by the two electron spectometers are discussed later.

\subsection{Rocket optical photometers}

The $3914 \AA$ radial photometer operated well and produced good data throughout the flight. The data reduction for the $3914 \AA$ photometer is described in the paper by McDade et al. (1991).

\subsection{Ground-based photometers}

The $1^{\circ}$ meridian photometers along the ChurchillLee Lake-Bird line produced good data during the entire flight. These data contain scans for $5577 \AA$ with excellent signal-to-noise ratios. The 4709 and $8446 \AA$ channels also produced usable data for tomographic analysis. The $4^{\circ}$ field meridian photometers operated well and data from these instruments were used for the $6300 \AA$ emission.

The zenith photometers at Churchill provided 


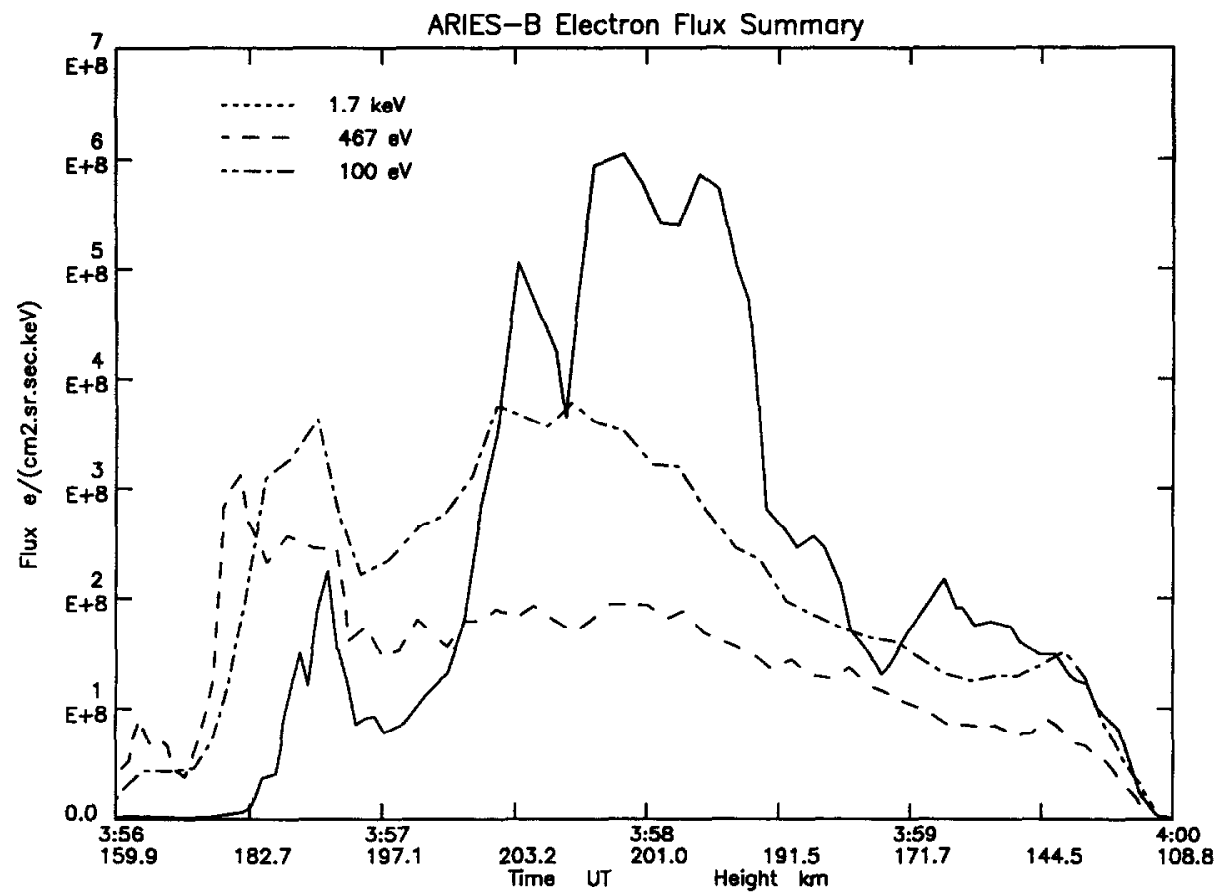

Fig. 5. SUMMARY OF FLUXES MEASURFD BY THE FIXED ENERGY PARTICle DETECTORS OF THE NRCC EXPERIMENT.

Times and corresponding rocket heights are indicated. The $1.7 \mathrm{keV}$ curve is shown as the solid trace.

measurements of the intensities in 15 channels as the arcs observed drifted southward before the rocket flight. Similar magnetic zenith data were obtained from the $4^{\circ}$ meridian scanner records at Gillam for the period of the rocket flight.

\subsection{Plasma probe}

The plasma probe operated well during the flight. Profiles for both electron density and temperature were obtained on the downleg passage through the southern arc. The results are described in the paper by Margot and McNamara (1991). Comparison of the electron density results with modelled values is described below.

\section{INTERPRETATION}

\subsection{Tomography from ground-based data}

In this section we present the results of a determination of the two-dimensional volume emission rate distribution in the plane of the trajectory, from the data obtained from the meridian scans of the three ground stations. These data are complemented by meridian scans from the rocket with the radially pointing $3914 \AA$ photometer. In principle, it might be poss- ible to combine the information provided by the rocket and ground photometers to provide the best overall solution. However, because of the temporal changes in the aurora during the flight, the approach chosen was to perform the analysis separately for the ground-based and rocket data and then to compare the results.

4.1.1. Tomographic inversion procedure. The method used to invert the ground-based data is based on the procedure described by Thomas and Donahue (1972) and Wasser and Donahue (1979). First, a set of $1 \times 1 \mathrm{~km}$ cells covering the region vicwed by the ground photometers was defined and filled with an initial set of equal volume emission rates. Next, the volume emission rate in each cell along each line of sight from the first ground station was scaled so that the integrated value along the line matched the observed intensity in that direction. The new array was then smoothed horizontally and vertically. Next, these steps were repeated for the second and the third ground stations. The whole procedure was then iterated until a stable solution was obtained. In the calculation of the results presented, no corrections were made for extinction and scattering. One of us (RLG) has carried out extensive numerical modelling tests of 
the effects of extinction and scattering for a variety of auroral distributions and on the basis of these, some corrections to the observed meridian scans were attempted. However, these corrections did not appear to improve the results of the inversion procedure and consequently the corrections were omitted in the final data analyzed. It should be noted that, as may be seen from Fig. 1, the elevation angles from the photometers to the important parts of the forms analyzed were never less than $30^{\circ}$.

The method was applied to the signals from the 5577,4709 and $8446 \AA$ channels from the $1^{\circ}$ photometers and for the $6300 \AA$ data from the other meridian photometers described in 2.5. Becausc the $1^{\circ}$ photometer data are obtained during 24-s cycles, the solutions apply to these predetermined scan intervals.

The result of the inversion procedure, applied, as an example, to the data from a time interval before the rocket launch, is reproduced in Fig. 6. The dashed curves in the left-hand panel show the observed meridian scans for the three ground stations. In this case, the scan from Churchill shows that the band was very close to the zenith and exhibited a simple, almost Gaussian, brightness profile in latitude. The views from Lee Lake and Bird approximate the classical auroral profile with a sharp lower border and a more extended upper region. The result of the tomographic inversion is shown in the right-hand panel and, as might be expected, shows a simple volume emission rate profile with a maximum near $133 \mathrm{~km}$. The solid curves on the left-hand panel show, for the three ground stations, the angular intensity distributions regenerated from the contours of the right-hand panel. The solid and dashed curves are almost identical. Since any physically realistic change in the derived height or latitude distribution of the volume emission rate would degrade this agreement, one can be fairly confident that the tomographic contours derived are close to being correct. A further detailed comparison of the original data, the regenerated data and the tomographic solution is presented later for the more complicated situation when the rocket was near apogec.

4.1.2. Application to the time of the rocket fight. The derived volume emission rate contours of the $5577 \AA$ emission, for a sequence of consecutive 48 -s time intervals during the rocket flight are summarized in Fig. 7. The contours for the 48-s intervals were obtained by averaging the results of the inversion of the data from two consecutive 24-s scans. This appeared to give better results than averaging the scans before performing the inversion.

The first two plots, for the time intervals from 3:55:36 to $3: 56: 24$ and from $3: 56: 24$ to $3: 57: 12$, show the development of the aurora during the upleg part of the flight. As the rocket passed up through the northern edge of the aurora, the main band beneath the trajectory was double with the northern component peaking at about $160 \mathrm{~km}$ accompanied by a

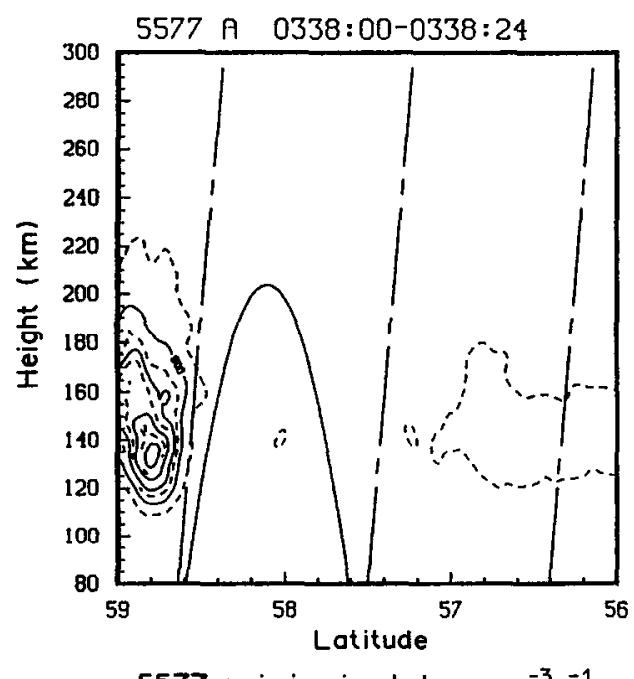

5577 emission in photons $\cdot \mathrm{cm}^{-3} \mathrm{~s}^{-1}$

FIG. 6. SAMPLE OF TOMOGRAPHIC INVERSION RESULTS FOR 03:38:00-03:38:24.

Left-hand panel, (--) $5577 \AA$ intensity measured by the meridian scanning photometers of the ground station line; (-) $5577 \AA$ intensity derived from the right-hand panel, which gives the volume emission rate contours derived by the tomographic inversion as described in the text. 

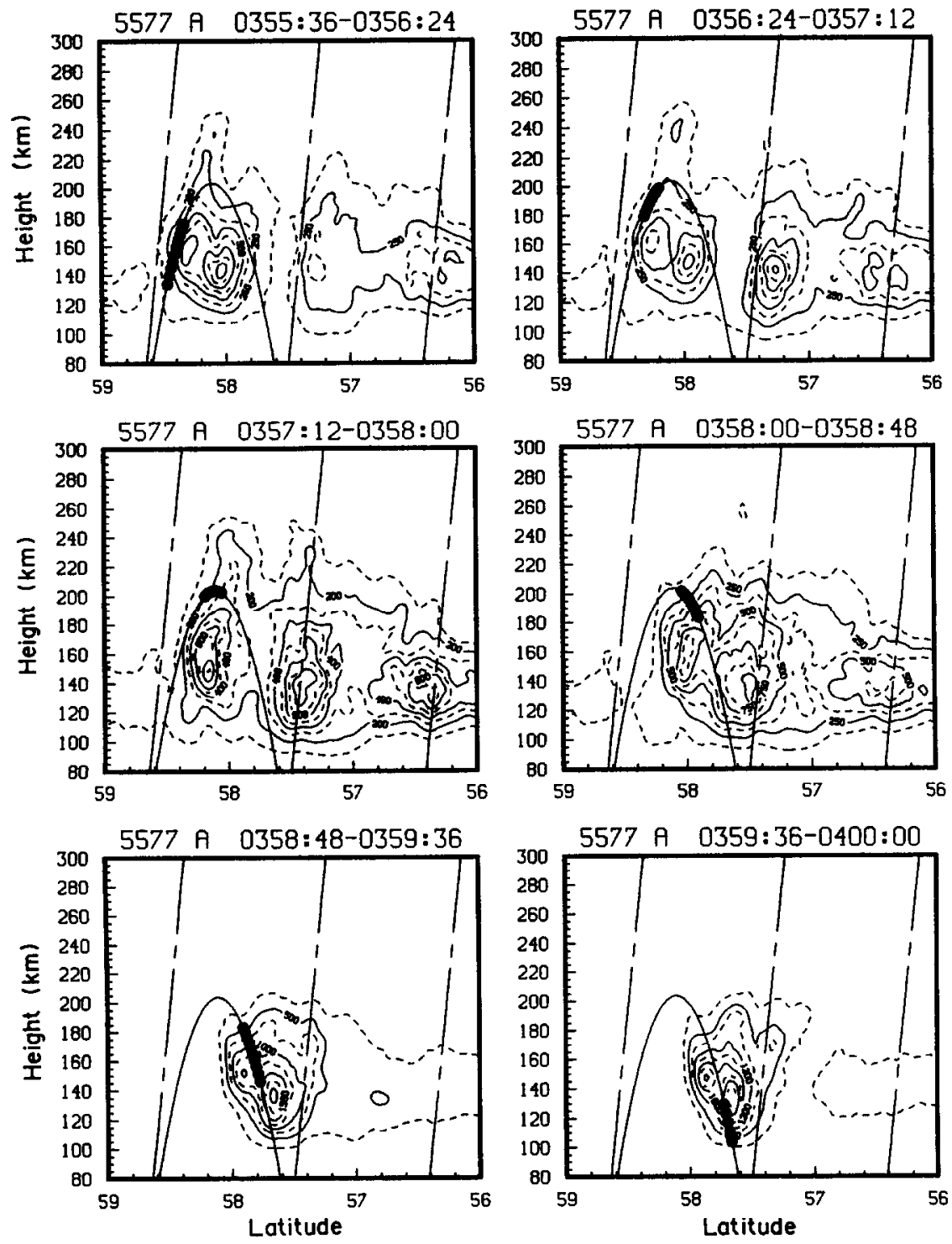

Fig. 7. $5577 \AA$ VOLUME EMISSION RATE CONTOURS DETERMINED AS FOR FIG. 6 FOR PERIOD OF ROCKET FLIGHT ABOVE $100 \mathrm{~km}$.

Each panel gives the results from the 48-s period as indicated. The rocket trajectory is plotted on each panel with black dots indicating positions of the rocket during the ground scans. Contours are marked with values in photons $\mathrm{cm}^{-3} \mathrm{~s}^{-1}$.

slightly lower and stronger equatorward component. In the second plot, centered at 3:56:48, as the rocket was approaching apogee, both forms weakened slightly and a separate arc strengthed south of the trajectory. This southern arc had a peak height of about $140 \mathrm{~km}$.

The next two plots, for 3:57:12 to $3: 58: 00$ and 3:58:00 to $3: 58: 48$, show the development of the aur- ora during the key period when the rocket was near apogee and located centrally above the electron flux producing the northern band. By this time the latter had become single again, with a peak-volume emission rate height in the neighborhood of $150-160 \mathrm{~km}$. The previously noted southern band persisted strongly through the time near apogee and the height of its maximum appeared to lie between 130 and $140 \mathrm{~km}$. A 
second southern arc appeared briefly at about $56.5^{\circ} \mathrm{N}$ latitude during the 3:57:00-3:58:00 interval.

The data plotted in Fig. 4 show that the aurora remained rather stable from $3: 57: 22$ to $3: 58: 10$, except for a steady southward drift of the northern band. The electron fluxes of Fig. 5 were also rather stable around this time, particularly from $3: 57: 36$ to $3: 58: 24$. It was a remarkable coincidence that, because the horizontal velocity matched the southward drift of the form, the rocket remained quite close to the field line connected with the arc (as seen from Fig. 3).

The rocket remained close to apogee during this period, and consequently the time interval from 3:57:36 to 3:58:24 was chosen for a detailed comparison of the observed height distribution with the theoretical distribution calculated by the theoretical model from the observed electron flux. This comparison is presented in Section 4.3.

The last two frames of Fig. 7, derived from scans obtained during the middle and lower parts of the descent phase, show that the northern peak weakened and almost coalesced with the southern form, which itself continued to grow stronger. It appears likely that the in situ measurements obtained during the time interval of the last frame of Fig. 7 correspond to the southern band. Clearly, the rocket did not intercept the particle flux exciting the southern form until it entered the edge of this form at a height below 140 $\mathrm{km}$ between 03:59:36 and 04:00:00. The measurements during this period of the flight are more fully discussed in Section 4.4.

The inversion procedure, described above, was applied to the meridian scans obtained simultaneously in the 5577 and $8446 \AA$ OI lines and the $4709 \AA \mathrm{N}_{2}^{+}$ band for all the time intervals of Fig. 7. In Fig. 8, we reproduce the set of volume emission rate contour plots for the time near apogee selected for study, i.e. between $3: 58: 36$ and $3: 59: 24$. A plot for $6300 \AA$ OI is also included in Fig. 8. The difference between the distributions for the four wavelengths will be discussed in Section 4.3. In a manner similar to Fig. 6, we show in Fig. 9 comparisons between the observed meridian scans from the three stations for each wavelength and the reconstructed scans recovered from the two 24-s tomographic inversions, which were averaged to give the plots of Fig. 8 .

\subsection{Tomography and height analysis of the rocket photometer data and comparisons with ground-based tomography}

The inversion of the data from the $3914 \AA$ radial rocket photometer is fully discussed in the paper by McDade et al. (1991). The results of this analysis may be compared with the ground results for the interval centered on 03:59:34, when the rocket was near 140 $\mathrm{km}$. The rocket result is shown in Fig. 8 of McDade et al. At this time the rocket is between the two forms and the rocket photometer signal should be quite sensitive to the height distribution of the emission. The height profiles, derived by McDade et al. and reproduced in their Fig. 14, give peak volume emission rate heights of about $130 \mathrm{~km}$ for the southern form and $140 \mathrm{~km}$ for the northern one. Their height profile for the northern form is derived from their Fig. 6 which gives a volume emission rate plot for a period centered on 03:58:57 when the rocket was at a height near 174 $\mathrm{km}$. Their data for the southern form are reproduced by the open circles in Fig. 10, while those for the northern form are reproduced in the same way in Fig. 11.

Two other methods were used by McDade et al. (private communication) to obtain height profiles from the rocket data. Both these methods should give valid height profiles, corrected for variations in primary particle number flux, provided there is little temporal variation in the energy distribution pattern.

The first method which was applied to the emission north of the rocket, was to use the northward horizontal signal vs height (with a correction for variations in total up-down intensity) to determine directly a profile for the northern form. The validity of this method is dependent on the circumstances (established by the ground data of Fig. 7), that there is no appreciable additional auroral emission north of the rocket and the absence of significant temporal variation during the downleg below $160 \mathrm{~km}$. This method gave a peak volume emission rate height of about $142 \mathrm{~km}$. The profile obtained is reproduced as the solid curve in Fig. 11.

The second method, applicable to the descent through the southern form, was to derive the volume emission rate profile by differentiation of the "up" signal after a correction for total intensity changes was made by dividing by the "up" + "down" signal. This is essentially the method originated by Dick and Fastie (1969). This procedure gave a peak very close to $130 \mathrm{~km}$; the complete profile so obtained is reproduced as the solid curve in Fig. 10. It should be noted that the profile was scaled to the maximum "updown" sum observed on the downleg and therefore represents the brightest profile crossed during the descent, i.e. a vertical slice through the core of the southern form. This is to be distinguished from the height distribution of the local volume emission rate derived and discussed in Section 4.4.2 below.

The profilc for the southern arc, abstracted from the ground-based tomography described in Section 4.1 , is also plotted in Fig. 10 (the method for the 

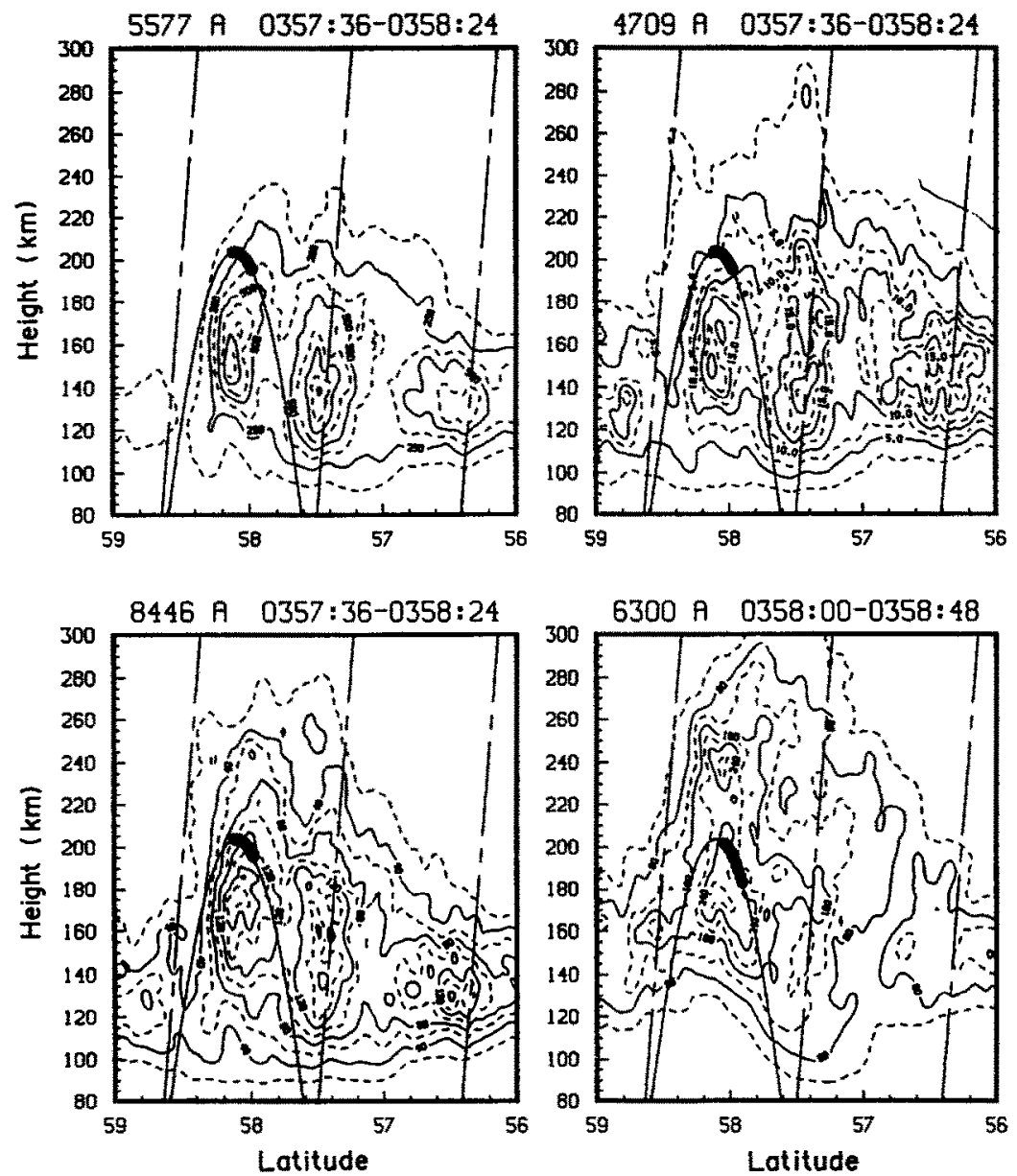

Fig. 8. VOLUME EMISSION RATE CONTOURS FOR 4709,5577 AND 8446 A EMISSIONS FOR THE APOGER PERIOD FROM 03:57:36 To 03:58:24.

A plot for the closest available period (03:58:00-03:58:48) for $6300 \AA$ is given in the fourth panel. It should be noted that the first three plots were produced by averaging the separate solutions for the periods 03:57:36-03:58:00 and 03:58:00-03:58:24.

ground-based profiles is described below in Section 4.3.3). The observed rocket profiles for $3914 \AA$ were converted to the volume emission rate for $4709 \AA$ by dividing by the transition probability ratio between the 0,0 and 0,2 bands. The profiles derived by the three methods agree well and indicate that the three techniques provide a good measurement of the height profile of the southern form at the time of the downleg passage through the aurora. The profile obtained by the ground-based method is slightly broader, as might be expected as a consequence of atmospheric scattering. The second maximum in the rocket profile obtained by the height differentiation method is not real, but is a consequence of the rocket having sampled the higher altitude northern band as it descended through the $200-160 \mathrm{~km}$ region (see Fig. 7). The tomographic rocket height profile is possibly affected by the temporal changes in the volume emission rate distribution documented in Fig. 7.

A comparison, for the northern band, between the results of the two rocket techniques discussed above (based on measurements during the downleg descent below $180 \mathrm{~km}$ ), and the ground-based tomographic profile obtained earlier during the time near apogee is shown in Fig. 11. Because the latter curve refers to an earlier time, it is likely that much of the difference between the rocket and ground-based curves is real. Moreover, the sidelook profile seen northward from the rocket, corresponds to the northern form with some contribution, at lower altitudes, from the sou- 

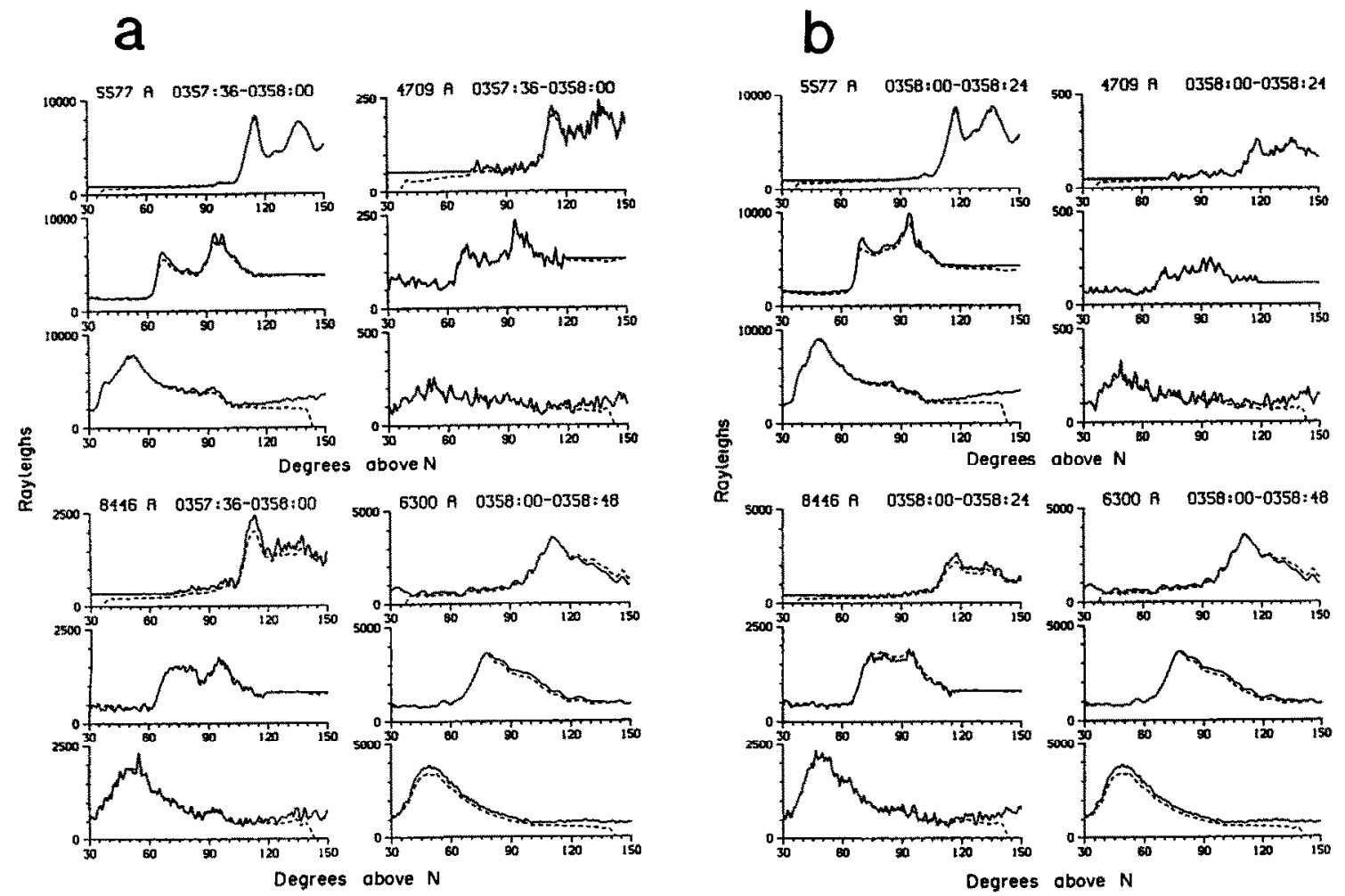

Fig. 9. A COMPARISON OF OBSERVED SCANS AND SYNTHETIC SCANS DERTVED FROM THE TOMOGRAPHICALLY DERIVED VOLUME EMISSION RATE DISTRIBUTIONS FROM WHICH THE PLOTS OF FIG. 8 WERE PREPARED.

The observed and reconstructed scans for the two 24 s periods described in the caption for Fig. 8 are presented separately, as panels (a) and (b).

thern band through which the trajectory passed. However, the ground-based results shown in Fig. 7 do not indicate that the peak of the northern form ever dropped below $147 \mathrm{~km}_{\text {, }}$ so that there is a definite difference between the rocket profiles shown in Fig. 11 and the final contour plots of Fig. 7 which, we are inclined to believe, may be due to scattering from the stronger southern form as the two bands merge with one another. The ground tomography should be much more reliable at apogee time when the northern and southern forms were well separated. It should be noted that during the time interval when the rocket was near apogee, it did not move far enough to provide a great enough change in viewpoint for good tomography.

\subsection{Modelling of height profiles of the northern arc observed near apogee}

4.3.1. Apogee electron flux spectra. The ground and rocket tomography provide a good basis for selecting the time for a critical comparison of auroral properties, predicted by excitation models and the optical and other obscrvations. As noted in Section 4.1, the time interval 03:57:36 to 03:58:24 is favorable, since the rocket is close to apogee and magnetically conjugate with the northern arc. Electron energy spectra for this time interval are reproduced in Fig. 12. This shows data, averaged over the pitch angle ranges 0 $90^{\circ}$ and $90-180^{\circ}$, both from the University of Saskatchewan soft electron spectrometer (McEwen, private communication) and from the NRCC electrostatic analyzer. The data from the two instruments are identified as from Instruments $A$ and $B$, respectively in Fig. 12. According to the NRCC data, the pitch angle distribution is isotropic from $0-60^{\circ}$ for the flux at 1.7 $\mathrm{keV}$, but has decreased by an order of magnitude by $120^{\circ}$, while at 0.5 and $0.1 \mathrm{keV}$ it is close to isotropic. The absolute accuracy of the data from the instrument $A$, which was carefully calibrated before and after the flight, is estimated to be about $10 \%$ (McEwen, private communication), while the calibration of instrument $B$ is less certain, but is believed to be accurate within a factor of 2 .

In fact, the two sets of measurements agree to within 
TOMOGRAPHIC AND ROCKET DATA SOUTHERN FORM

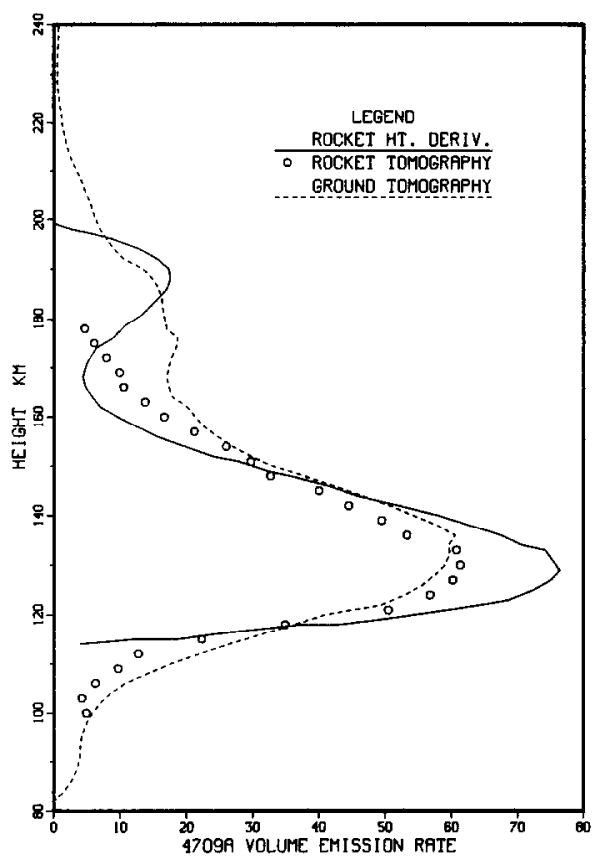

FIG. 10. COMPARISON OF HEIGHT PROFILE MEASUREMENTS FOR THE SOUTHERN FORM BY ROCKET AND GROUND-BASED METHODS. $(\longrightarrow)$ Height differentiation of the total intensity corrected upward rocket photometer signal; $(O)$ tomographic inversion of rocket photometer "meridian" scans; (--) tomographic inversion of data from ground meridian scanner chain.

a factor of 2 both in the magnitude of the differential flux and spectral distribution. The NRCC downward spectrum shows a peak at about $1.5 \mathrm{keV}$. This peak, although reproducible from one scan to another, does not appear in the more accurate data from the other spectrometer; the origin of the discrepancy is not clear.

In the modelling reported below, we have used both the McEwen downward electron spectrum, which is identified as Spectrum A, and the NRCC downward spectrum, identified as Spectrum B. The differences in the calculated volume emission rates and peak heights for the two electron spectra provide an indication of the sensitivity of the profiles to the details of the primary electron spectrum.

4.3.2. Auroral excitation model. In order to make some preliminary comparisons between the observed profiles and theoretical predictions, it was convenient to use the model described by Vallance Jones (1975). From this model, profiles for ion production rates, electron densities and some auroral feature emission
TOMOGRAPHIC AND ROCKET DATA NORTHERN FORM

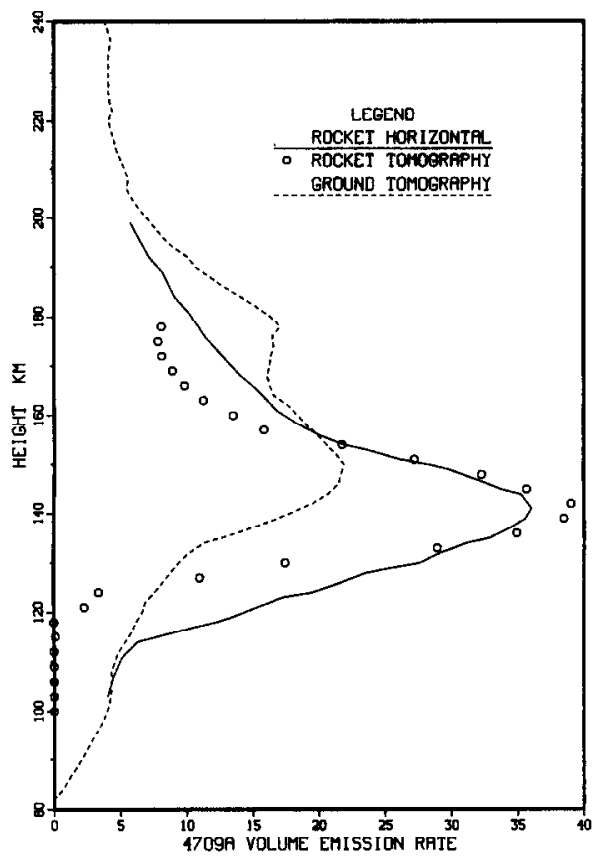

Fig. 11. COMPARISON OF HEIGHT PROFILE MEASUREMENTS OF THE NORTHERN FORM BY ROCKET AND GROUND-BASED METHODS.

(-) Rocket horizontal view method; $(O)$ rocket tomography; (-- ) tomographic inversion of data from ground meridian scanner chain.

rates may be calculated by means of the method described by Rees and Jones (1973). This procedure, which is based on the assumption that the energy given to secondary electrons is deposited locally, is reasonably accurate at heights below $150 \mathrm{~km}$ for ion production rates and emissions from excited ions such as the $\mathbf{N}_{2}^{+} 1 \mathrm{~N}$ bands. This is illustrated by a comparison, in Fig. 13, between profiles calculated in this way and by the more physically correct electron transport method, which was developed by Strickland et al. $(1976,1983)$. In this test the same model atmosphere (Jacchia, 1977, with $1000^{\circ}$ exospheric temperature) and the same electron fluxes were used. The results in Fig. 13 show that, for total ionization rates, the local energy deposition model described gives satisfactory results within the range of energies and heights concerned in this study.

The application of the model to the 5577 and $8446 \AA$ OI emissions may not be so satisfactory. For the former, uncertainty as to the mechanisms for the excitation of this emission renders the modelled profile 


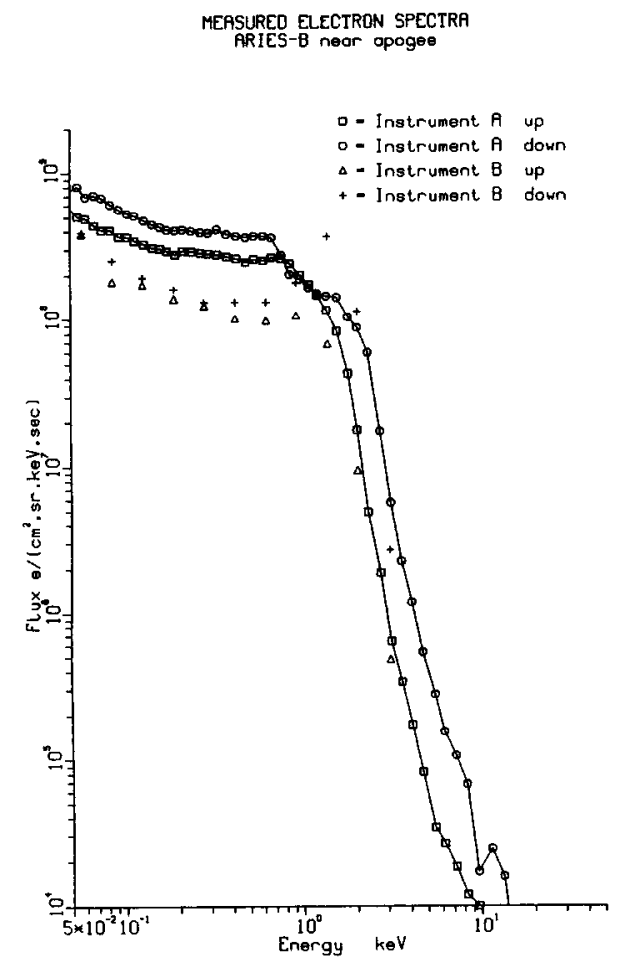

Fig. 12. ELECTRON SPECTRA OBTAINED NEAR APOGEE FOR THE PERIOD 03:57:36-03:58:24 BY MCEWEN (PRIVATE COMMUNICATION; MCEWEN et al, 1991) (LABELLED INSTRUMENT A) AND THE NRCC EXPERIMENT (LABELLED INSTRUMENT B). In each case spectra are given as averages over the pitch angle ranges $0-90^{\circ}$ (down) and $90-180^{\circ}$ (up).

less reliable than for $4709 \AA \mathrm{N}_{2}^{+}(1 \mathrm{~N})$. The theoretical profile was calculated by the method described by Gattinger et al. (1985), with the important production processes of $\mathrm{O}\left({ }^{\prime} \mathrm{S}\right)$ being collisional excitation of $\mathrm{O}$ by secondary electrons and energy transfer from $\mathrm{N}_{2}$ (A) with an empirically chosen value of $20 \%$ for the yield of $\mathrm{O}\left({ }^{1} \mathrm{~S}\right)$ in the $\mathrm{N}_{2}$ (A)/O quenching reaction. There is no theoretical or laboratory justification for the latter choice, except that it does give a reasonable value for the $I(5577 \AA) / I\left[\mathrm{~N}_{2}^{+}(1 \mathrm{~N})\right]$ ratio and reproduces an approximately constant ratio for the corresponding volume emission rates with height, as has often been observed. It should be noted however that the laboratory measurements of the yield for the $\mathrm{N}_{2}(\mathrm{~A}) / \mathrm{O}$ reaction are closer to $75 \%$ (Piper, 1982; De Souza et al., 1985). In the particular case examined in this paper, the agreement between model and observation would be improved by adopting a higher value for the yield factor (see Fig. 16b); unfortunately the model treatment of secondary electron fluxes is not rigorous enough, nor is our knowledge of the atomic oxygen
MODEL DATA

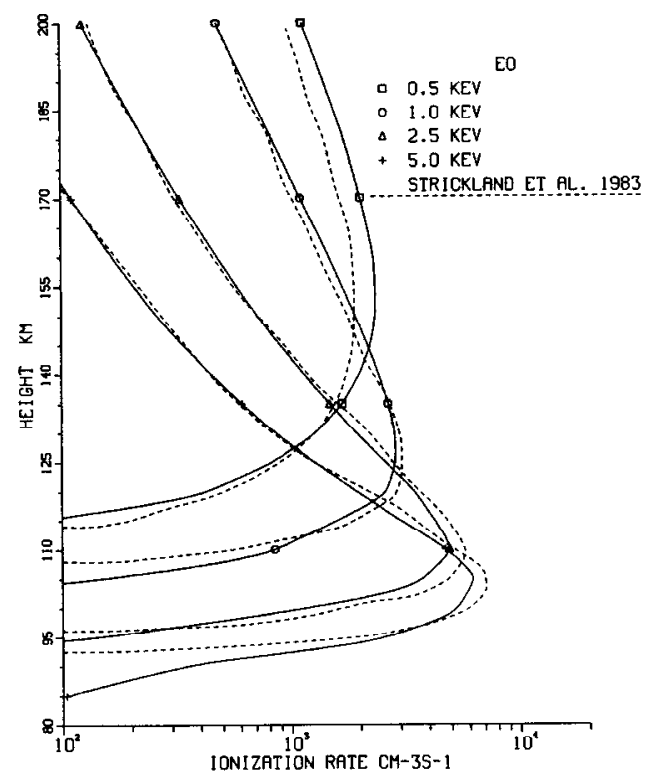

Fig. 13. Comparison of IONIZATION RATE PROFILES CALCULATFD RY A IOCAL ENERGY DEPOSITION MODEL (VALLANCE JONES, 1975) AND ELECTRON TRANSPORT MODEL OF STRICKLAND $e t$ al. (1983) FOR MAXWELLIAN FLUXES, WITH THE CHARACTERISTIC ENERGIES INDICATED AND A JACCHIA (1977) ATMOSPHERE WITH AN EXOSPHERIC TEMPERATURE OF $1000 \mathrm{~K}$.

concentration sufficiently certain to justify fitting the results by adjusting the $O\left({ }^{\prime} S\right)$ yield factor.

The $8446 \AA$ profile was modelled by noting that the excitation cross section for electron impact (Gulcicek et al., 1988) is somewhat similar in shape to the cross section for $\mathrm{N}_{2}$ (a) as used in the model. The 8446 $\AA$ emission rate was obtained simply by proportion taking into account the ratio $[\mathrm{O}] /\left[\mathrm{N}_{2}\right]$ and the ratio of excitation cross section peaks for $\mathrm{N}_{2}$ (a) and 8446 $\AA$ OI. This procedure is no more than a first approximation, in that any differences in the $8446 \AA$ and $\mathrm{N}_{2}$ (a) cross sections will lead to errors, as may radiative transfer effects in the cascade processes leading to the upper state of $8446 \AA$ OI.

Measured downward electron spectra from Fig. 12 were used as input to the model. An MSIS86 atmosphere (Hedin, 1987) for the time of the flight was used.

No primary ion particle measurements were made but optical measurements of $\mathrm{H} \beta$ show that the contribution from proton excitation was small. $\mathrm{H} \beta$ measurements from Bird indicate that the zenith intensity in the region of the forms measured in this study, was about $35 \mathrm{R}$. According to the calculations 


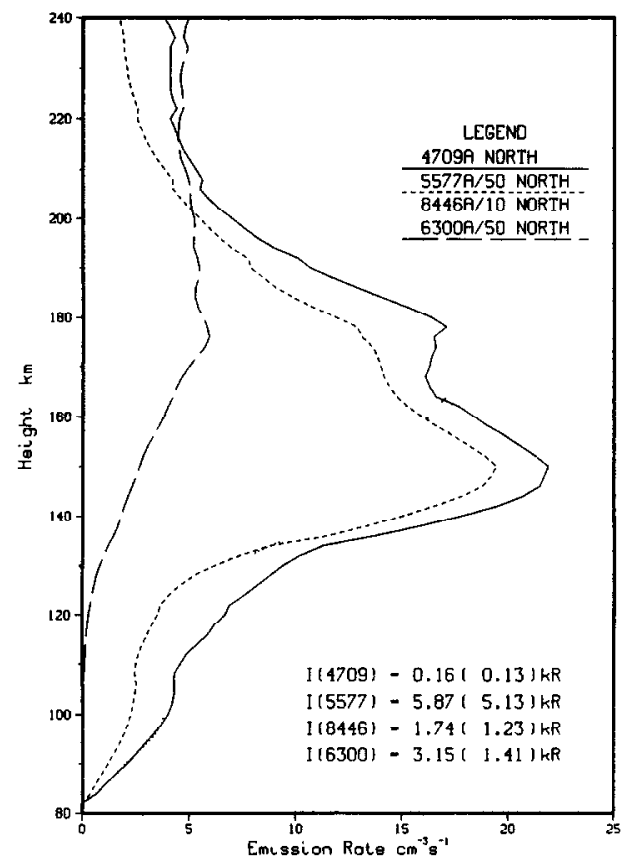

FIG. 14. OBSERVED EMISSION PROFILES FOR THE $4709 \AA \mathrm{N}_{2}^{+}$ (1N) AND 5577,6300 AND $8446 \AA$ OI EMISSIONS DERIVED FROM GROUND-BASED TOMOGRAPHY FOR THE NORTHERN ARC FOR THE PERIOD 03:57:36-03:58:24 U.T.

Magnetic zenith values for the emission intensities, integrated to $300 \mathrm{~km}$, are given on the plot; the values in brackets are integrated to $200 \mathrm{~km}$ for directed comparison with the model results.

of Van Zyl et al. (1984), the ratio $I(\mathrm{H} \beta) / I(4709)$ should be about 4 for protons of average energy 10 $\mathrm{keV}$ and 1.0 for $100 \mathrm{keV}$ protons. Thus if the $\mathrm{H} \beta$ emission were produced by $100 \mathrm{keV}$ protons, $35 \mathrm{R}$ of the observed integrated $4709 \AA$ intensity might be due to proton excited emission. This would represent a possibly significant $22 \%$ of the observed emission according to the data of Fig. 14. (The profiles of Fig. 14 were derived from the contours of Fig. 8 as described in the next section.) However $100 \mathrm{keV}$ protons produce a peak ionization rate near $105 \mathrm{~km}$ (Eather, 1970 ; Jasperse and Basu, 1982). A 22\% component with a peak at this height would be quite noticeable in the $4709 \AA$ profile of Fig. 14 . If the $\mathrm{H} \beta$ were produced by $10 \mathrm{keV}$ protons the profile would be similar to that observed, but the total contribution to the integrated $4709 \AA$ intensity would be reduced to about $6 \%$, so that the effect would be negligible. For the $5577 \AA$ profile no reliable theoretical calculations are possible, but the measurements of Eather (1968) indicate that the ratio $I(5577) / I(\mathrm{H} \beta)$ is typically about 10 , so that the zenith intensity due to protons would again be about $6 \%$ of the observed 5.9 kR. Consequently, it appears justifiable to neglect proton impact excitation in the modelling comparisons.

4.3.3. Comparison with tomographic measurements. As noted in Section 4.1, Fig. 8 shows contour plots, from ground-based tomography, of the volume emission rates of the 5577,6300 and $8446 \AA$ OI lines and the $4709 \AA \mathrm{N}_{2}^{+}$band. The first three contour plots correspond exactly to the time interval selected for analysis (as noted above) for 3:58:36-3:59:24. The fourth plot gives the volume emission rate distribution obtained by the same method for the $6300 \AA$ OI line for the period from 03:58:00 to 03:59:36. As described above in Section 2.5, the $6300 \AA$ data were obtained with a different set of meridian scanning photometers with an angular resolution of $4^{\circ}$ (or better) and a scan repetition time of about $30 \mathrm{~s}$. Consequently, the results shown are not exactly comparable to those presented in the first three panels of the figure. However, because of the longer radiative lifetime of the $O\left({ }^{1} D\right)$ state and the much broader height profile of this emission the results shown should still be useful for comparison with those for the other emissions.

Inspection of the plots of Fig. 8 show that the contours for $5577 \AA$ OI and $4709 \AA \mathrm{N}_{2}^{+}$are rather similar, except that the latter are more noisy. The contours for the $8446 \AA$ OI emission peak at higher altitude and decrease more slowly with height than those for $5577 \AA$ OI and $4709 \AA$. Although the contour plot for $6300 \AA$ is quite noisy, the general distribution of $6300 \AA$ emission is centered over that of the other emissions, but with a profile which has a very broad maximum in the $180-250 \mathrm{~km}$ region.

As a final step in the analysis of the observations, field aligned profiles for the four emissions were calculated from Fig. 8 by averaging the volume emission rates as a function of height along the magnetic field lines connecting to the rocket during the interval of the ground based observation. The positions of the rocket during the time period arc shown by the black dots on the trajectory on Fig. 8.

The observed tomographic profiles for the emissions are reproduced together in Fig. 14. Intensity values, integrated up to $300 \mathrm{~km}$, are given on the plots; the values in brackets are integrated to $200 \mathrm{~km}$ for comparison with the theoretical values, which have an upper limit of $200 \mathrm{~km}$, the height at which the particle measurements were made. It is striking that the observed 5577 and $4709 \AA$ profiles are very similar, with a value close to 37 for the $I(5577) / I(4709)$ ratio, which corresponds to about 7.4 for $I(5577) /(4278)$ on the basis of the $0,1 / 0,2$ band transition probabilities.

An overview of the model profile results is given 


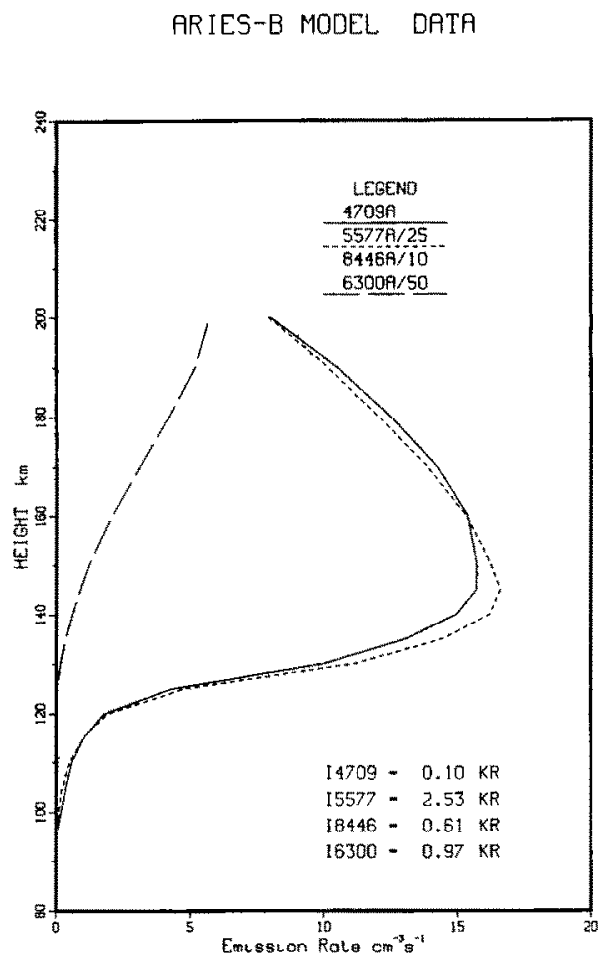

Fig. 15. Modelled volume emission Rate PROFILES FOR tHE SAME FEATURES AS FOR FIG. 14 FOR THE OBSER VED PRIMARY SPECTRUM A FOR THE APOGEE PERIOD 03:57:36-03:58:24 U.T. Magnetic zenith intensities, integrated to $200 \mathrm{~km}$ are given on the plot.

by Fig. 15, which shows respectively the theoretical profiles for the $4709 \AA \mathrm{N}_{2}^{+}(1 \mathrm{~N})$ band and the 5577 , 8446 and $6300 \AA$ OI lines. The profiles were calculated using the model described in Section 4.3.2 and the downward primary spectrum measured by Instrument A as reproduced in Fig. 12. Because the measurements were made near $204 \mathrm{~km}$, the flux was assumed to be incident at the $200 \mathrm{~km}$ level in the model.

The scales for the $4709 \AA$ curves are the same in both the observed and model profiles. Apart from some irregularities in the tomographic profile, the two height distributions are very similar in magnitude and general height distribution. The value of the ratio $I(5577) / I(4709)$ of about 25 is somewhat lower than the observed value noted above. The model prediction for $8446 \AA$ shows a profile displaced upward by a significant amount and this is matched within experimental error by the observed profile. More detailed comparisons for each emission will be described next.

4.3.4. Detailed comparison of modelled and observed profiles. In Fig. 16a, the model profiles computed are

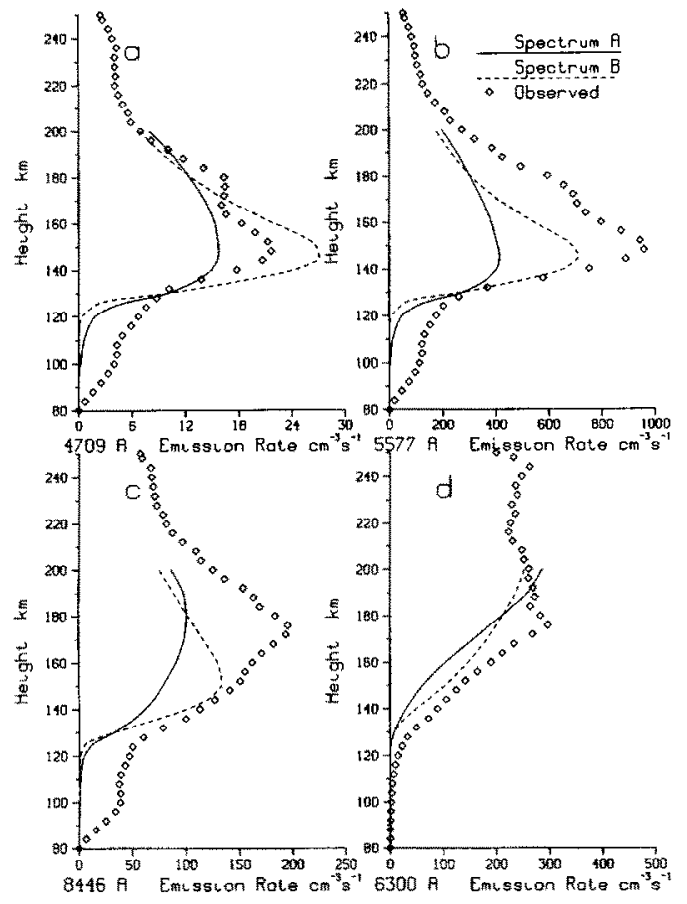

Fig. 16. (a) MODELLED AND OBSERVED VOLUME EMISSION PROFILES FOR THE $4709 \AA \mathrm{N}_{2}^{+}$(IN) EMISSION.

The modelled profiles were calculated for the downward primary electron spectra of Fig. 12 (identified as described in Section 4.3.1). The points for the observed profile as replotted from Fig. 14. (b) Similar to (a) for the $5577 \AA$ OI emission. (c) Similar to (a) for the $8446 \AA$ OI emission.

(d) Similar to (a) for the $6300 \AA$ OI emission.

compared with the observed profile for the $4709 \AA$ $\mathrm{N}_{2}^{+}(1 \mathrm{~N})$ emission. The observed profile has a peak volume emission rate a little higher than the theoretical profile based on the electron spectrum $A$ and a little less than the theoretical profile based on spectrum B as defined in Section 4.3.1. The height distribution is somewhat similar for the observed profile and that based on the spectrum $A$. The profile based on the spectrum $B$ is narrower, no doubt as a consequence of the peak at $1.5 \mathrm{keV}$ in this spectrum.

A similar comparison was made for the $5577 \AA$ OI emission and the results are presented in Fig. 16b. The observed peak volume emission rate for $5577 \AA$ is about double the modelled values based on electron spectrum $A$ and about $40 \%$ greater than that based on electron spectrum B. Again the profile based on the spectrum $B$ is somewhat narrower in its height distribution.

The modelled and observed profiles for the 8446 $\AA$ OI emission are reproduced in Fig. 16c. The height distribution of the profile based on spectrum A agrees 
much better with the observed one than does that based on the spectrum B. As in the case of $\lambda 5577$, the predicted intensity is lower than observed.

Modelled and observed profiles for $\lambda 6300$ are reproduced in Fig. 16d. In the region below $180 \mathrm{~km}$ where the model might be expected to be valid, the profiles are similar, with the observed emission rates being somewhat higher than the modelled values.

The result that both $I(5577)$ and $I(8446)$ are approximately double the predicted values could indicate an enhancement of [O] over the MSIS 86 value used in the modelling. This is a possibility which will be subject to test when the predicted values can be recalculated using a more accurate model. In principle the $8446 \AA$ observations should settle the question of the correct value for [O] and then the $5577 \AA$ result could provide guidance for deciding the question of the excitation processes for $O(1 S)$.

\subsection{Analysis of data from the southern arc traversed on the downleg}

The profile for the three emissions can likewise be extracted from the ground-based tomography results for the southern form traversed during the downleg passage. These are reproduced in Fig. 17. Again, the $5577 \AA$ and $4709 \AA$ profiles are almost identical with an intensity ratio close to 48 , i.e. $I(5577) / I(4278) \simeq$ 9.6 .

This value differs somewhat from the value of 7.4 derived in Section 4.3.3 from the northern arc profiles of Fig. 14. If the difference is real, the simplest interpretation would be to ascribe the change to the greater mean height of the northern arc combined with a hypothetical decrease with height in the ratio $\eta(5577) / \eta(4278)$. However, for the profiles of Fig. 17 this ratio appears, if anything, to fall off slightly more slowly with height. In the case of Fig. 14 there is some tendency for the ratio to decrease with height as expected. The aurora was comparatively weak so it is hardly likely that the difference between the ratio for the two arcs can be ascribed to gross composition effects, although the somewhat higher average value of the ratio for the two arcs (compared to the data of Vallance Jones and Gattinger, 1972) could be a composition effect. Another possibility is that the difference between the ratios of the integrated intensities may be due to some subtle instrumental effect, possibly arising from residual differences in the calibrations of the three photometers. For these reasons we prefer to regard the difference between $I(5577) / I(4278)$ ratios for the two arcs as being within the range of experimental error of the tomographic method and to adopt a value of $8.5 \pm 1.0$ as the best estimate.

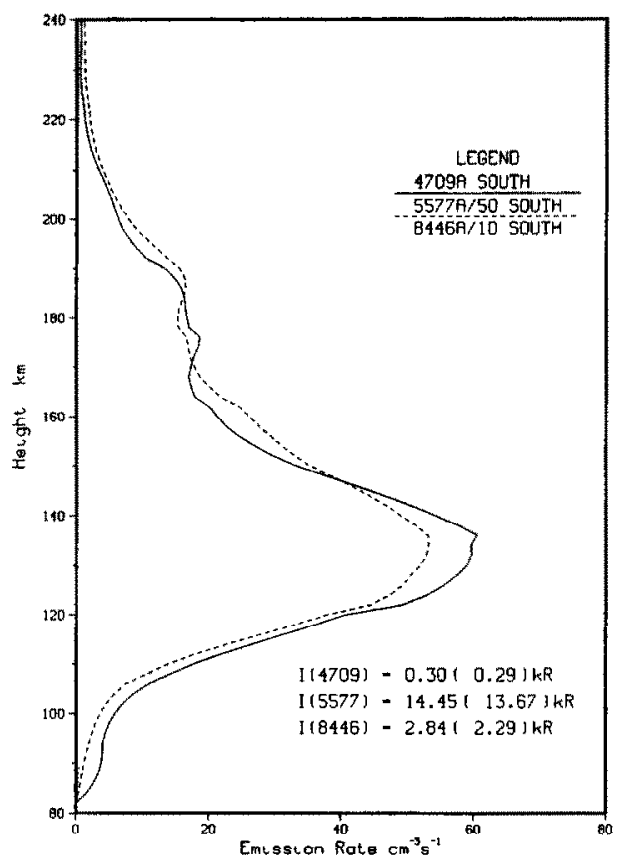

Fig. 17. ORSER VED EMISSION PROFILES FOR THE $4709 \AA \mathrm{N}_{2}^{+}$ (IN) 5577 AND $8446 \AA$ OI EMISSIONS DERIVED FROM GROUNDBASED TOMOGRAPHY FOR THE SOUTHERN ARC DURING THE DOWNLEG PASSAGE FOR THE PERIOD 03:59:36-04:00:00 U.T. Magnetic zenith values for the emission intensities, integrated to $300 \mathrm{~km}$, are given on the plot; the values in brackets are integrated to $200 \mathrm{~km}$ for direct comparison with the model results.

It is interesting that the peak of the $8446 \AA$ OI emission is no longer displaced significantly above that of 5577 and $4709 \AA$, although its volume emission rate falls off much more slowly with height.

As noted above, Fig. 10 shows that the profiles of the southern arc obtained by rocket tomography and by up-down analysis of data on the downleg are all very similar. It is of interest to attempt to determine what primary electron spectrum would be consistent with these height profiles.

4.4.1. Derivation of primary electron spectrum from downleg measurements. In order to determine what input primary spectrum could reproduce the observed profiles, a comparison was made by adjusting the primary electron flux spectrum until a satisfactory match was obtained with the $\mathrm{N}_{2}^{+}$profiles. The results for the best match to the points of the rocket tomographic profile of Fig. 10 are plotted on Fig. 18. The theoretical profile is for a Maxwellian primary flux spectrum with a characteristic energy of $0.5 \mathrm{keV}$ accelerated by $2.0 \mathrm{keV}$. This gives the spectral distribution shown on the insert in Fig. 18. It might be described 


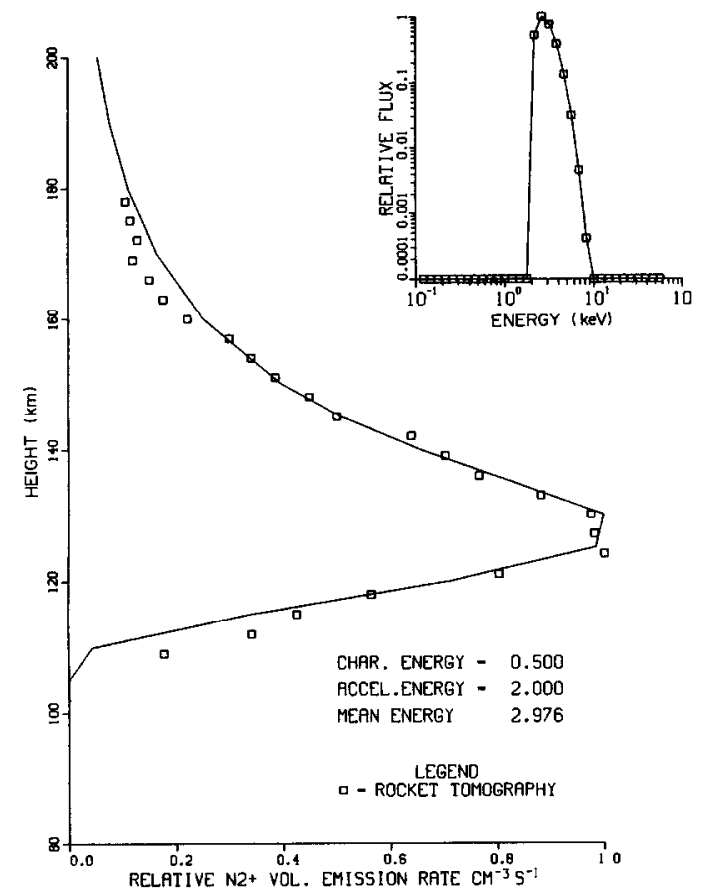

Fig. 18. MATCH OF PROFILE OF $\mathrm{N}_{2}^{+}(1 \mathrm{~N})$ EMISSION OBSERVED BY ROCKET TOMOGRAPHY BY MCDADE et al. (1991) WITH PROFILE MODELLED WITH ACCELERATED MAXWELLIAN SPECTRUM AS DESCRIBED IN SECTION 4.4.1.

The rocket profile was converted to the volume emission rate for the $4709 \AA$ band. Each curve is normalized to 1 at its peak. The inset shows a plot of the primary flux spectrum used in the modelling.

as a slightly broadened $3 \mathrm{keV}$ flux. An almost equally good match is obtained with a Gaussian primary flux centered on $3.0 \mathrm{keV}$ with a full width at half peak of $2.9 \mathrm{keV}$. As a further test, the matching procedure was performed for the points of the ground tomography profile of Fig. 10. In this case the best matching primary spectrum was Maxwellian with a characteristic energy of $0.7 \mathrm{keV}$ and an acceleration energy of 1.0 $\mathrm{keV}$. The result is shown in Fig. 19.

It is of interest to note that energy spectrum which appears to fit best the southern form approximates what would be obtained by accelerating the flux exciting the northern arc by a $1-2 \mathrm{kV}$ potential drop.

The model curves for the $4709,5577,6300$ and $8446 \AA$ emissions obtained with the quasi-monoenergetic flux of Fig. 18 (inset) are shown in Fig. 20. Although the ratio of the volume emission rates of the 8446 and $4709 \AA$ features increases steadily with height, the profile is so sharply peaked in this case that there is little upward displacement of the maximum of

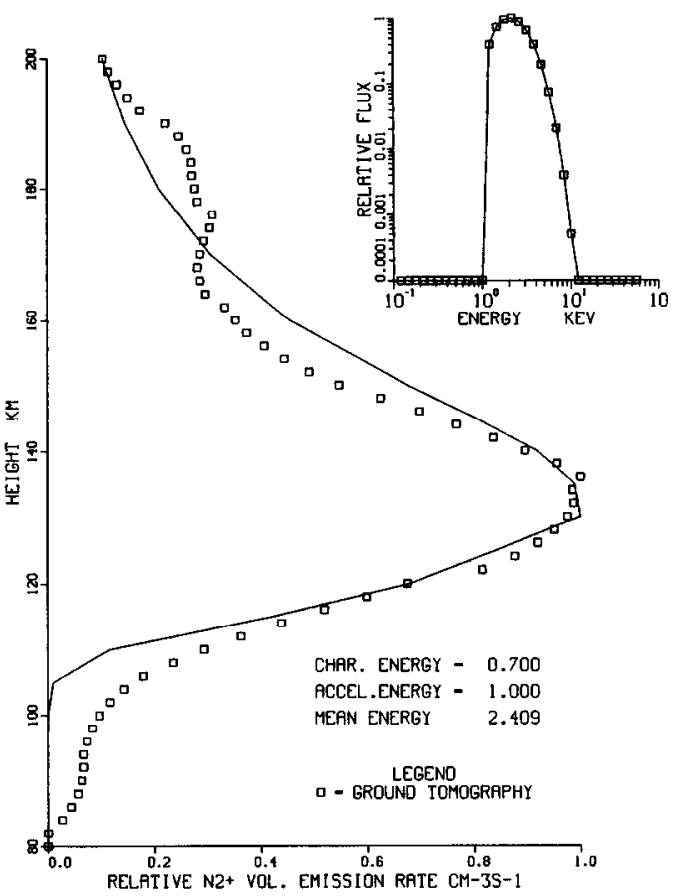

Fig. 19. Similar to Fig. 18 eXCEPT THAT THE MATCH IS to THE PROFILE OF THE $\mathrm{N}_{2}^{+}$(IN) BAND DERIVED BY GROUNDBASED TOMOGRAPHY AS DESCRIBED IN THIS PAPER.

The parameters of the matching spectrum are given on the plot.

$8446 \AA$. This contrasts with the behavior with the softer fluxes of the northern form.

Margot and McNamara (1991) found reasonable agreement between their observed downleg electron density profile and a modelled profile calculated for a $3 \mathrm{keV}$ monoenergetic flux. They also found general agreement between their electron temperature profile and a modelled profile based on the same primary electron flux. This does not necessarily mean that the actual exciting flux was $3 \mathrm{keV}$ monoenergetic, because there may be spatial and temporal components in the observed profile along the trajectory. It does indicate that the observed local electron densities and temperatures measured are consistent with one another, since in the steady state both the electron density and the electron temperature are determined by the ionization rate.

4.4.2. Modelling of electron densities from optical data on the downleg. The plot given by Margot and McNamara (1991) for the downleg is reproduced as the dash-dot curves on the right-hand panels of Fig. 21. It is important to note that this plot gives the local electron density measured along the trajectory. The most interesting part of the trajectory below $180 \mathrm{~km}$ 
ARIES-B MODEL DATA

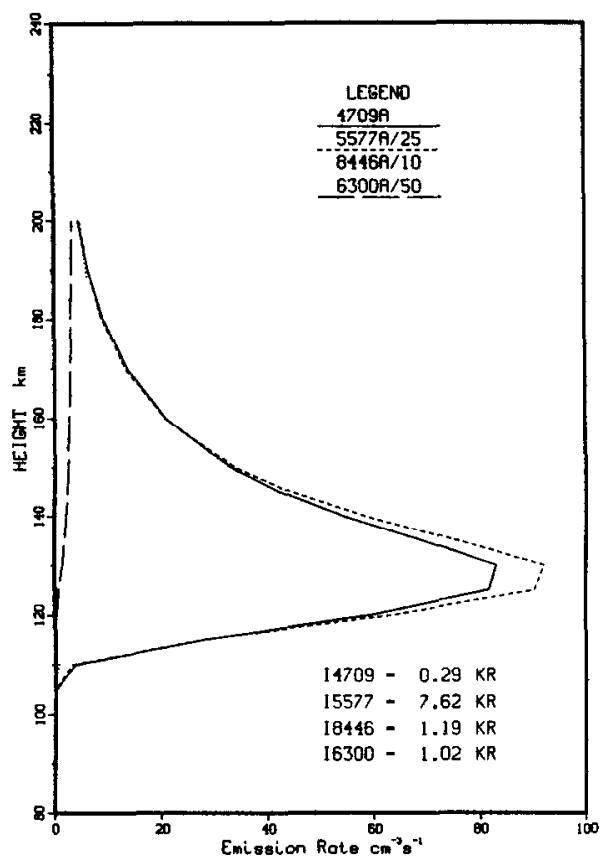

Fig. 20. MOdel CuRVes, AS FOR FIG. 15, BUT FOR THE PRIMARY ELECTRON SPECTRUM OF FIG. 18.

Magnetic zenith intensities, integrated to $200 \mathrm{~km}$ are given on the plot.

is covered by the last two plots of Fig. 7 , i.e. from 03:58:48 to 04:00:00. The variation of electron density vs height is influenced by the rocket motion in latitude, which carries it from a position almost above the northern arc, across the "valley" between the two forms, and then finally to descend just north of the core of the southern form. Thus the curve in Fig. 21b is by no means a simple plot of $n$ (e) vs $h$ along a field line, although it probably approximates such a plot in the region of peak electron density.

The calculations to be described in the next paragraphs were carried out to test whether the observed electron densities could be understood in terms of the results of the ground-based and rocket tomographic plots.

In principle, the electron density along the trajectory can be calculated from the optical volume emission rate data of Fig. 7, from which the temporal variation of $\eta(4709)$ and hence the ion production rate can be derived at points along the trajectory over the period of the flight. The time variation of the electron density at each point can then be computed with the help of a time-dependent ion chemistry model, such

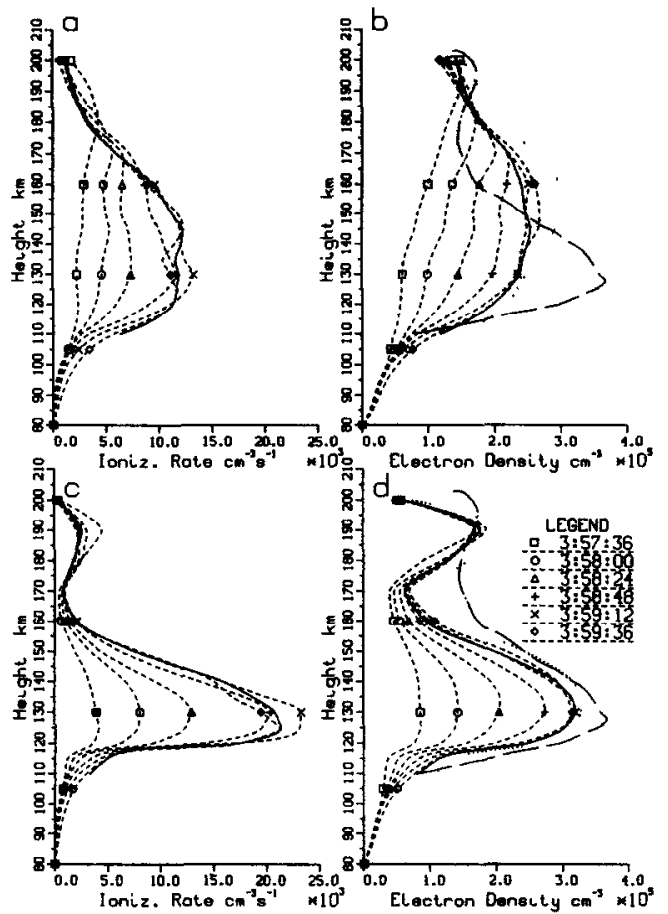

Fig. 21. (a) THE DASHED CURVES GIVE THE IONIZATION RATE PROFILES ALONG THE ROCKET TRAJECTORY AT 24-S INTERVAIS DERIVED FROM THE OPTICAL DATA OF FIG. 7.

The solid line is interpolated from the same data using the time-height table for the rocket and so gives the local ionization rate which should have been seen by the rocket. (b) Electron densities (dashed curves) along the rocket trajectory calculated by time dependent model from the ionization rate variation given by panel (a); the solid curve is the electron density which would have been seen by the rocket as interpolated from the dashed curves. The dotted curve is the equilibrium electron density derived from the solid curve of panel (a). The chain-dot curve is the observed electron density along the trajectory as measured by the plasma probe (Margot and McNamara, 1991). (c) Similar to panel (a) except that the absolute value of the ionization rate at each height was scaled to agree with the values observed on the downleg by McDade et al. as described in the text. (d) Similar to panel (b) but derived from the scaled input data of panel (c).

as that described by Vallance Jones et al. (1987). Finally theoretical values for the electron density can be picked out for the instants in time at which the rocket would have reached each point on the trajectory. These values can then be compared with the measurements from the plasma probe.

An input dataset for points on the downleg trajectory was prepared from data similar to that of Fig. 7 except that the volume emission rate distributions were derived for the longer period from 03:54:00 to 04:00:00 at intervals of $24 \mathrm{~s}$ (the basic repetition rate 
of the ground photometers). The $5577 \AA$ data were used to give the best signal-to-noise ratio. A constant value of 10 was taken for the ratio $\eta(5577) / \eta(4278)$ as derived in Sections 4.3.3. and 4.4 from the tomographic profiles based on longer period of integration. The derived values of $\eta(4278)$ were interpolated at (4-s) intervals to provide a smooth input to the model. Ion production rates were derived from the values of $\eta(4278)$ by means of the equations given by Vallance Jones (1974).

The resulting ion production rates for points along the rocket trajectory are plotted at 24-s intervals in Fig. $21 \mathrm{a}$ as the dashed curves. The solid curve gives the values of the ion production rate as seen from the rocket, i.e. it presents values [abstracted from the complete $\eta_{1}(h, t)$ dataset] for the ion production rate, $\eta_{\text {, }}$, at the instant the rocket reaches each height level.

The time-dependent ion chemistry model was then run using the complete $\eta_{1}(h, t)$ datsaset starting at 03:54:00 for each height and the electron densities derived plotted as the dashed curves on Fig. $21 \mathrm{~b}$ in a similar way to Fig. 21a. Again, the solid line gives the theoretical electron density which should have been encountered on the downleg.

The dash-dot curve on Fig. 21b, gives the actual variation of electron density measured by Margot and McNamara. Clearly the modelled trajectory profile is seriously in error.

To discover the reason for the discrepancy, a check on the model was first carried out by computing the approximate equilibrium electron density from the solid curve of Fig. $21 \mathrm{~b}$ and employing the approximate relation:

$$
n_{\mathrm{e}}=\sqrt{(}\left(\eta_{1} / \alpha\right)
$$

where $\eta_{1}$ is the total ionization rate and $\alpha$ is the effective electron recombination rate coefficient, as given by Wickwar et al. (1975). The $n_{e}$ profile, so calculated from the instantaneous ionization rate profile shown on Fig. 21a, is plotted as the dotted curve on Fig. 21 b. This profile is quite similar to the model profile given by the solid line. This indicates that the ion production rates were varying slowly enough for the electron density to be quite close to the steady-state values given by equation (1) and provides a check that the reaction rates used in the model are consistent with the effective recombination rates given by Wickwar et al. (1975).

It appears from Fig. $21 \mathrm{~b}$ that the electron densities inferred from the optical data are low by about $30 \%$ at the electron density peak and high above $150 \mathrm{~km}$. One must conclude that the corresponding optical volume emission rates are underestimated by a factor of two near the peak of the profile and overestimated in the region above $150 \mathrm{~km}$. The inversion procedure was repeated several times from different initial conditions without any substantial change in the result. Thus, the discrepancy does not appear to be due to any failure of the inversion algorithm to yield a unique solution.

Although the profiles of Fig. 10 show that there is good agreement between the ground and rocket tomographic profiles of the $\mathrm{N}_{2}^{+}$emission, there is a small but significant difference in the location of the rocket trajectory, relative to the maximum of the volume emission rate contours, in the last panel of Fig. 7 and the corresponding figure of McDade et al. (1991). According to the latter, the rocket passed very close to the point of maximum emission rate, while in the former, the maximum lies slightly to the south. Thus, the ionization rate along the rocket trajectory shown in Fig. $21 \mathrm{a}$ is significantly underestimated near 130 $\mathrm{km}$. The geometry is also unfavorable along the upper part of the trajectory which, as may be seen from Fig. 7 , lies in the region of volume emission rate minimum between the north and south forms above $150 \mathrm{~km}$. Consequently, it is not surprising that the derived volume emission rates in this region are less accurate.

It was found that an improved prediction of the electron density along the trajectory could be achieved by combining the ground-based optical data with those from the rocket photometer. As noted earlier, the optical observations from the rocket are not subject to errors due to atmospheric scatter. Moreover, as shown below, a good estimate of the local volume emission rate of the $\mathrm{N}_{2}^{+}$emission along the trajectory can be obtained directly from the rocket photometer data. On the other hand, the ground data can better take account of the temporal variations in the twodimensional volume emission rate distribution. Thus we assume:

(i) that the ground-based data should give the best estimate of the temporal variation of the ionization rate at points on the trajectory over the whole time period considered; but

(ii) local measurements from the rocket should be used to calibrate the absolute value of the groundbased estimates.

The required local values of $\eta(3914)$ were obtained directly by multiplying the "up"-"down" profile of Fig. 10 by the "up"-"down" sum used in the normalization which preceded the height differentiation. This reintroduces, along the trajectory, the spatial and temporal variation removed in the normalization. The solid curve in Fig. 21c gives the resulting trajectory profile for $\eta_{1}$ derived from the values of $\eta(3914)$. The dashed curves on this figure show the data of Fig. 2la "calibrated' according to the solid curve. The time- 
dependent model was then run with the renormalized ionization rate profiles to produce the curves of Fig. 21d, which are thus corrected versions of those of Fig. $21 \mathrm{~b}$. The solid curve again gives the predicted electron density for the downleg while the dotted curve gives the equilibrium value based on equation (1).

The correction of the height profile on the basis of the rocket data leads to better agreement between the predicted and observed electron density profiles in the region of the peak. Indeed the modelled profiles fall off somewhat more rapidly with height than the observed one up to $170 \mathrm{~km}$. The higher value of the modelled electron density in the $190-200 \mathrm{~km}$ region is probably due to temporal variations of electron flux or energy distribution.

The conclusion from this above analysis is that the measured electron densities in the region of the downleg maximum are consistent with the optical measurements. One cannot infer the primary electron spectrum from the electron density profile, except on the assumption that there was no latitude variation in precipitation.

\subsection{Ground-based magnetic zenith measurements}

4.5.1. Measurements from Fort Churchill and Lee Lake. The magnetic zenith measurements from the specialized zenith-pointing instrument at Churchill and from the $4^{\circ}$ scanner at Lee Lake, provide an independent set of data which can be related to the overall interpretation of the event studied.

In the case of the Churchill observation, the measurement is of the passage of the arc system through the local magnetic zenith in the period from 03:35 until 04:00, when the rocket had descended to $100 \mathrm{~km}$. As may be seen from Fig. 3, there is a period of intensification in the magnetic zenith from about $03: 37$ to $03: 45$, followed by a short strong brightening about 03:51. This behavior is reffected in the magnetic zenith intensities for $\lambda 5577, \lambda 6300$ and $\lambda 4278$, which are plotted in the lower panel of Fig. 22. In the middle panel are plotted the ratios $I(5577) / I(4278)$ and $I(6300) / I(4278)$. The former ratio remains almost constant in the range of $8-10$ with no obvious change during the intensification of the aurora. However, the ratio $I(6300) / I(4278)$ shows a significant decrease correlated with the auroral intensification.

The data given in Fig. 22, obtained from the Churchill photometer before the launch, cannot be compared with certainty with the primary electron characteristics determined during the rocket flight. Nevertheless, because of the apparent continuity of existence of the equatorward drifting arc system, it is of interest to compare the electron energies inferred from the zenith optical ratios with those measured by the rocket. Average electron energies were estimated from the $I(6300) / I(4278)$ intensity ratio using the relation adopted by Vallance Jones et al. (1987) and are plotted in the upper panel of Fig. 22. Values obtained fall in the range $1.5-2 \mathrm{keV}$ both during the zenith passage of the band about 03:39 and, during the later brightening, about 03:51. This is somewhat higher than the energies measured by the rocket instruments, which gave average energies in the range $0.9-1.2 \mathrm{keV}$. It is very possible that this aurora was more energetic, since it was brighter $[I(5577)=5-7$ $\mathrm{kR}$ ] compared to the arc traversed near apogee (Fig. 15).

For Lee Lake, the zenith data cover the growth and decay of the southern arc between 03:56 and 04:04. As seen from Fig. 7, this arc appeared south of the Lee Lake zenith, intensified and moved poleward into the zenith. This is the form through which the rocket descended, so that additional in situ measurements are available. The data for $\lambda 5577, \lambda 6300$ and $\lambda 4278$ are plotted in Fig. 23. As for the Churchill data, the $I(5577) / I(4278)$ ratio remains almost constant (but in the range of 6-8), with no obvious change during the intensification of the aurora, while again the ratio $I(6300) / I(4278)$ shows a significant decrease correlated with the auroral brightening. The $\lambda 4278$ intensity before and after the intensification is about 200 $\mathrm{R}$ and consequently the value of $I(6300) / I(4278)$ at these times is probably less trustworthy (because of the possibility of scattering and background contamination), but the value at the time of peak intensity around $03: 58: 30$ should be reliable.

The measurements presented in Fig. 23 again cannot be compared directly with the rocket observations, because as noted above, the electron flux exciting the southern form was not directly measured. The average energy of the incident flux from the observed values for the ratio $I(6300) / I(4278)$ is plotted in the top panel of Fig. 23. At the time of peak intensity, the inferred average electron energy is about $3.0 \mathrm{keV}$. As noted above, this value is in agreement with the value inferred in Section 4.4.1 from the height distribution.

4.5.2. Discussion and comparison with tomographic results. It should be noted that the data presented in Fig. 22 cover the period before the rocket flight when the arc system drifted southwards across the Churchill zenith, while the Le Lake observations of Fig. 23 give zenith intensity measurements of the southern arc, through which the rocket passed on the downleg. The plots of Fig. 7 show that this arc was moving northward during the time of the flight and crossed the Lee Lake field line at about 03:58. The difference between the values of $I(5577) / I(4278)$ above Churchill and 


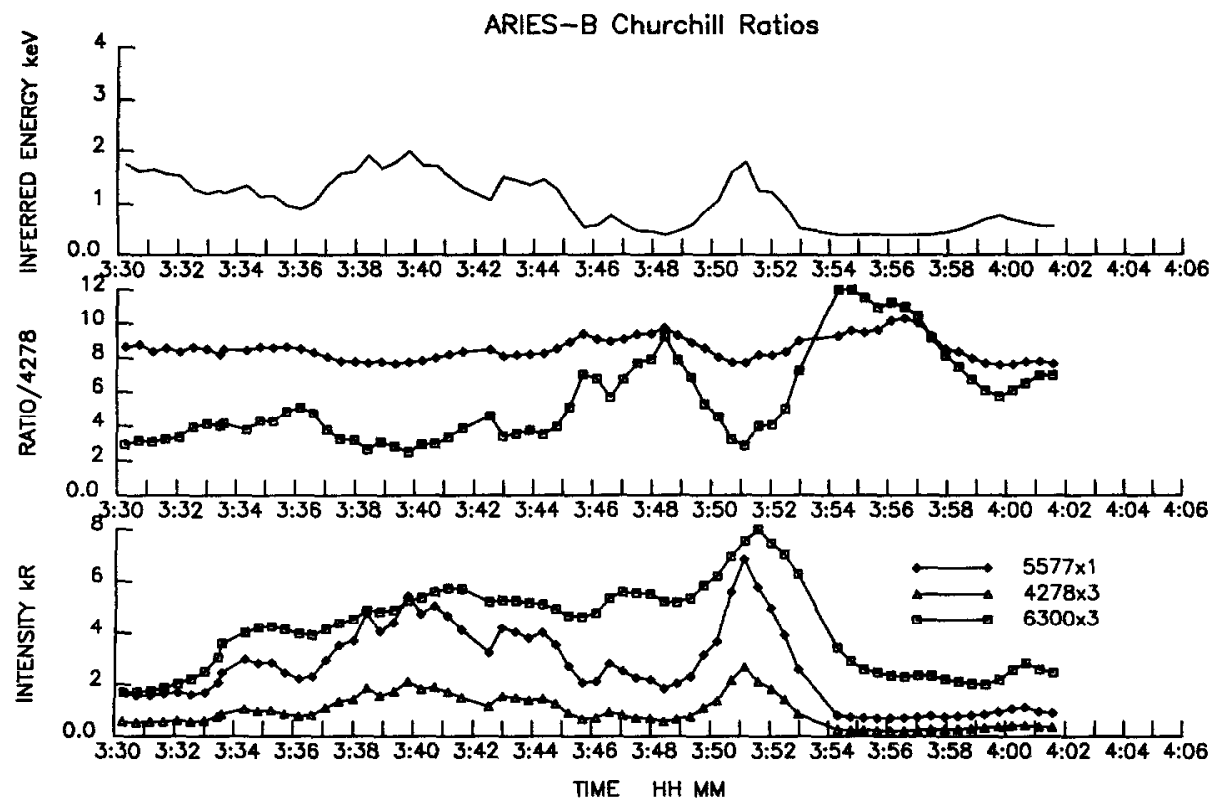

Fig. 22. MaGnetic Zenith INTENSities of 5577, 6300 AND $4278 \AA$ emissions From ChURChill (LOWER PANEL).

Corresponding intensity ratios are plotted in the middle panel and energies inferred from the relation of Vallance Jones et al. (1987) in the upper panel. The observations extend back to the period before the flight when the arc system drifted southwards through the station zenith.

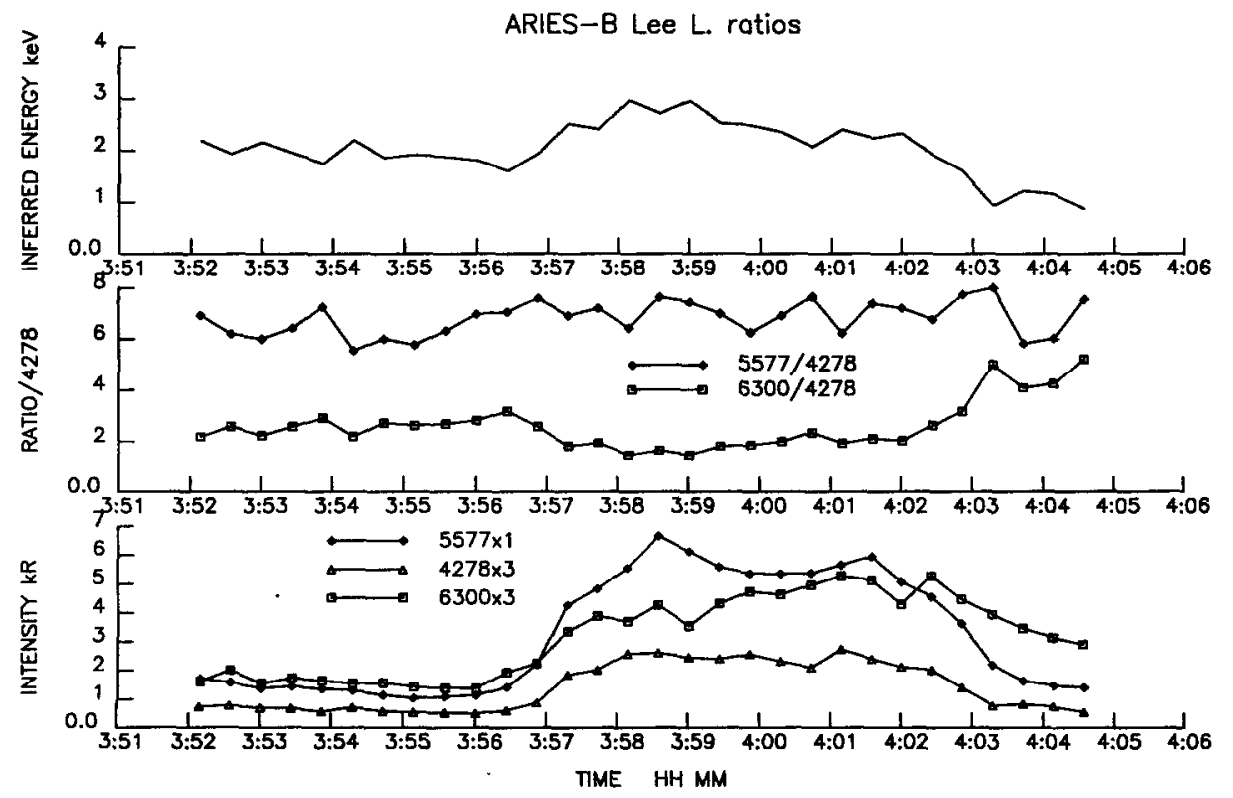

Fig. 23. Similar to Fig. 22, but for zenith measurements from Lee Lake obtained from the $4^{\circ}$ MERIDIAN SCANNING PHOTOMETER. 
Lee Lake can hardly be real and falls within the 10$15 \%$ absolute accuracy of the ground photometers. There is also a similar difference between the groundbased value from Lee Lake of about 7 for this ratio and that of about 9.6 from Fig. 17. The zenith intensity of 25577 in Fig. 17 is about $14 \mathrm{kR}$ compared to the maximum value of about $7 \mathrm{kR}$ in Fig. 23. However, from Fig. 7 it is clear that the southern arc brightened by about a factor of two after it moved north of the Lee Lake zenith.

\section{SUMMARY AND CONCLUSIONS}

(1) An auroral arc system excited by soft electrons, was studied with a combination of in situ measurements and optical tomographic techniques, using data from a photometer on a horizontal, spinning, rocket and three meridian scanning photometers set out in a line under the rocket trajectory. The analysis was simplified in that the magnetic field direction was approximately in the plane of the rocket trajectory and because the spin axis of the rocket was held perpendicular to this plane by an attitude control system.

(2) The ground-based scanner data were successfully inverted to provide a set of volume emission rate distributions in the plane of the rocket trajectory with a time resolution of 24 or $48 \mathrm{~s}$ during the rocket flight. Results were obtained for the 4709,5577 and $8446 \AA$ emissons with supplementary distributions at $6300 \AA$. Volume emission rate profiles, derived from these distributions, peaked at about $150 \mathrm{~km}$ for 5577 and $4709 \AA$, while the $8446 \AA$ peaked at about 170 $\mathrm{km}$ with a more extended height distribution.

(3) The rocket photometer gave comparable volume emission rate distributions for the $3914 \AA$ emission, as reported in a separate paper by McDade $e t$ al. (1991).

(4) Instruments on the rocket measured the primary electron flux during the flight and, in particular, the flux precipitating into the auroral arc overflown at apogee (McEwen et al., 1991). The local electron flux and temperature were measured by probes on the rocket (Margot and McNamara, 1991). The electron density measurements on the downleg were modelled using ion production rate data derived from the optical results.

(5) Model calculations of the emission height profile based on the measured electron flux agree with the observed profiles.

(6) The height distribution of the equatorward band, through which the rocket passed during the descent, measured by the ground and rocket tomographic techniques are in good agreement. Comparison of this profile with model profiles indicates that the exciting primary spectrum may be represented by an accelerated Maxwellian or a Gaussian distribution centered at about $3 \mathrm{keV}$. This distribution is close to what would be obtained if the electron flux exciting the poleward form were accelerated by a 1-2 $\mathrm{kV}$ upward potential drop.

(7) The relative height profile for the volume emission rate of the $5577 \AA$ OI emission is very similar to that of the $4709 \AA \mathrm{N}_{2}^{+}$band for both the forms measured. The ratio for $I(5577) / I(4278)$, obtained by integration of the tomographic profiles, was about 7 for the northern arc overflown at apogee and 10 for the southern arc at the time of downleg passage. The difference between these values may not be significant and we prefer an average value of 8.5 for the best estimate of this ratio from the rocket data.

(8) Although no critical direct comparison was possible, the auroral intensities and the values of the intensity ratio, $I(6300) / I(4278)$ measured in the magnetic zenith from the ground during the period before and during the rocket flight, are consistent with the primary electron fluxes and height distributions measured from the rocket. The measured values for the ratio, $I(5577) / I(4278)$ remained in the range $6-8$ for Lee Lake and $8-10$ for Churchill. It is likely that the difference between the mean values for the two stations falls within the $10-15 \%$ calibration error for the two different instruments. The overall average value of $I(5577) / I(4278)$ again falls near 8.5 , in agreement with the rocket measurements. This value is slightly higher than those reported by Gattinger and Vallance Jones (1972) and this may possibly indicate an enhancement of the atomic oxygen concentration at this low level of auroral activity. The values of $I(5577)$ and $I(8446)$ modelled using the electron flux spectrum measured at apogee are also significantly lower than those observed. This also would be consistent with values of $[\mathrm{O}]$ above those of the model atmosphere.

(9) It would be desirable to repeat the modelling calculations with a more sophisticated model to take full advantage of the results obtained. This is particularly true of the 5577 and $8446 \AA$ height profiles for which the model employed is no more than a rough approximation. The comparison for $\lambda 8446$ should provide some guidance as to the true concentration of atomic $O$ so that the comparison for $\lambda 5577$ might then provide a more critical test of the excitation mechanism of $O\left({ }^{\prime} S\right)$.

Acknowledgements - It is a pleasure to acknowledge the assistance of the personnel of the Canadian Centre for Space Research of the National Research Council in the planning both of the rocket flight and the ground station logistics for 
the ARIES campaign. In particular the essential role played by $\mathrm{Mr}$ Hal Roberts, the Mission controller in the development and launching of the payload and Mr Dale Crook in setting up the Lee Lake ground station. Likewise, personnel at the Churchill Research Range played a vital part. National Research Council technical personnel responsible for the vital task of operating the ground-based instrumentation include Dale Tyler, François Gauthier, Don Bradley and John Vollenweider. Contributions are acknowledged from a number of scientists who participated in the planning of the campaign and in the provision of rocket and ground instrumentation. These include Drs G. Witt, I. Robertson, L. Cogger, R. Van Es, G. Shepherd, W. Morrow, M. Morrow, J. McConnell, P. Forsyth, D. Wallis, B. Solheim, W. Ward, R. Wiens, B. Whalen, J. Hecht, A. Christensen and J. McDougall. We are especially grateful to Drs D. J. McEwen and David Strauss for providing electron spectrometer data and for many useful discussions. The analysis of the ARIES-B rocket photometer measurements was supported at the University of Michigan by NASA grant NAG5-670. Work at the University of Saskatchewan was supported by the Natural Sciences and Engineering Research Council of Canada.

\section{REFERENCES}

Bclon, A. E., Romick, G. J. and Rees, M. H. (1966) Electron energy spectra from luminosity profiles of aurora. Planet. Space Sci. 14, 597.

Bogdanov, N. N., Yagodkina, O. I., Tarasova, T. M., Davidov, V. S., Morozov, B. I. and Lazarev, A. I. (1981) Comparison of the behaviour of first and second positive systems of molecular nitrogen in polar aurora, Results of Researches on the international Geophysical Projects. Aurora Airglow 28, 40.

Cummings, W. D., Laquey, R. E., O'Brien, B. J. and Walt, M. (1966) Rocket borne measurements of particle fluxes and auroral light. J. geophys. Res. 71, 1399.

Daniell, R. E. and Strickland, D. J. (1986) Dependence of auroral middle UV emissions on the incident electron spectrum and neutral atmosphere. J. geophys. Res. 91, 321.

Deans, A. J. and Shepherd, G. G. (1978) Rocket measurements of oxygen and nitrogen emissions in the aurora. Planet. Space Sci. 26, 319.

Deans, A. J., Shepherd, G. G. and Evans, W. F. J. (1976) Rocket measurement of the $\mathrm{O}_{2}\left(\mathrm{~b}^{1} \Sigma_{\mathrm{g}}^{+}-\mathrm{X}^{3} \Sigma_{\mathrm{g}}^{-}\right)(\mathrm{O}-\mathrm{O})$ band in aurora. J.geophys. Res. 81, 6227.

De Souza, A. R., Gousset, G., Touzeau, M. and Tu Khiet (1985) Note on the determination of the efficiency of the reaction $\mathrm{N}_{2}\left(\mathrm{~A}^{3} \Sigma\right)+\mathrm{O}\left({ }^{3} \mathrm{P}\right) \rightarrow \mathrm{N}_{2}+\mathrm{O}\left({ }^{1} \mathrm{~S}\right)$. J. Phys. B 18, L661.

Dick, K. A. and Fastie, W. G. (1969) Up-down photometers for auroral profile studies. Appl. Opt. 8, 2457.

Donahue, T. M., Parkinson, T. and Zipf, E. C. (1968) Excitation of the auroral green line by dissociative recombination of the oxygen molecular ion: analysis of two rocket experiments. Planet. Space Sci. 16, 737.

Eather, R. H. (1968) Spectral intensity ratios in protoninduced auroras. J. geophys. Res. 73, 119.

Eather, R. H. (1970) Ionization produced by auroral proton precipitation, Ann. Geophys. 26, 609.

Evans, D. S., Jacobsen, T., Maehlum, B. N., Skovli, G. and Wedde, T. (1972) Low energy electron precipitation and the ionospheric $F$-region in and north of the auroral zone. Planet. Space Sci. $20,233$.

Feldman, P. D. (1978) Auroral excitation of optical emis- sions of atomic and molecular oxygen. J. geophys. Res. 83, 2511.

Feldman, P. D. and Doering, J. P. (1975) Auroral electrons and oplical emissions of nitrogen. J. geophys. Res. 80, 2808.

Gattinger, R. L., Harris, F. R. and Vallance Jones, A. (1985) The height, spectrum and mechanism of type-B red aurora and its bearing on the excitation of $\mathrm{O}\left({ }^{\prime} \mathrm{S}\right)$ in aurora. Planet. Space Sci. 33, 207.

Gattinger, R. L. and Vallance Jones, A. (1972) The intensity ratios of auroral emission features. Ann. Geophys. 28, 91.

Gerdjikova, M. G. and Shepherd, G. G. (1987) Evaluation of auroral $5577-\AA$ excitation processes using Intercosmos Bulgaria 1300 satellite measurements. J. geophys. Res. 92, 3367.

Gulcicek, E. E., Doering, J. P. and Vaughan, S. O. (1988) Absolute differential and integral electron excitation cross sections for atomic oxygen- 6 . The ${ }^{3} \mathrm{P} \rightarrow{ }^{3} \mathrm{P}$ and ${ }^{3} \mathrm{P} \rightarrow{ }^{5} \mathrm{P}$ transitions from 13.87 to $100 \mathrm{eV}$. J.geophys. Res. 93,5885 .

Hecht, J. H., Christensen, A. B., Strickland, D. J. and Meier, R. R. (1989) Deducing composition and incident electron spectra from ground-based auroral optical measurements: variations in oxygen density. J. geophys. Res. 94, 13553.

Hedin, A. E. (1987) MSIS-86 thermospheric model. $J$. geophys. Res. $92,4649$.

Jacchia, L. G. (1977) Thermospheric temperature, density and composition: new models. Special Report 375, Smithsonian Astrophysical Observatory, Cambridge, MA.

Jasperse, J. R. and Basu, B. (1982) Transport theoretic solutions for auroral protons and $\mathrm{H}$ atom fluxes and related quantities. $J$. geophys. Res. 87, 811.

Lummerzheim, Rees, M. H. and Anderson, H. R. (1989) Angular dependent transport of auroral electrons in the upper atmosphere. Planet. Space Sci. 37, 109.

Margot, J. and McNamara, A. G. (1991) Comparison of plasma density and electron temperaturc profiles during the auroral modelling campaign ARIES. Can. J. Phys., 69, 950 .

McDade, I. C., I loyd, N. D. and Llewellyn, E. J. (1991) A rocket tomography measurement of the $\mathrm{N}_{2}^{+} 3914 \AA$ emission in an auroral arc. Planet. Space Sci. 39, 895.

McEwen, D. J., Strauss, D. L., Whalen, B. A. and Yau, A. W. (1991) An analytical study of measured electron influx and optical intensity for a steady aurora. In preparation.

Parkinson, T. D. (1971) A phase and amplitude study of auroral pulsations. Planet. Space Sci. 19, 251.

Parkinson, T. D. and Zipf, E. C. (1970) Energy transfer from $\mathrm{N}_{2}\left(\mathrm{~A}^{3} \Sigma_{u}^{+}\right)$as a source of $\mathrm{O}(\mathrm{I} S)$ in the aurora. Planet. Space Sci. 18, 895.

Parkinson, T. D., Zipf, E. C. and Donahue, T. M. (1970) Rocket investigation of the auroral green line. Planet. Space Sci. 18, 187.

Piper, L. G. (1982) The excitation of $O\left({ }^{1} S\right)$ in the reaction between $\mathrm{N}_{2}\left(\mathrm{~A}^{3} \Sigma_{\mathrm{u}}^{+}\right)$and $\mathrm{O}\left({ }^{3} \mathrm{P}\right)$. J. chem. Phys. 77, 2373.

Rees, M. H. and Jones, R. A. (1973) Time dependent studies of the aurora: II. Spectroscopic morphology. Planet. Space Sci. 21, 1213.

Rees, M. H. and Lummerzheim, D. (1989) Characteristics of auroral electron precipitation derived from optical spectroscopy. J. geophys. Res. 94, 6799.

Rees, M. H., Romick, G. J., Anderson, H. R. and Casserly, R. T. Jr. (1976) Calculation of auroral emissions from measured electron precipitation : comparison with observation. J. geophys. Res. 81, 5091. 
Rees, M. H., Stewart, A. I., Sharp, W. E., Hays, P. B., Hoffman, R. A., Brace, L. H., Doering, J. P. and Peterson, W. K. (1977) Coordinated rocket and satellite measurements of an auroral event: 1 . Satellite observations and analysis. J. geophys. Res. 82, 2250.

Rees, M. H., Walker, J. C. G. and Dalgarno, A. (1967) Auroral excitation of the forbidden lines of atomic oxygen. J. geophys. Res. 15, 1097.

Sharp, W. E. and Hays, P. B. (1974) Low energy auroral electrons. J. geophys. Res. 79, 4319.

Sharp, W. E. and Torr, D. G. (1979) Determination of the auroral $O\left({ }^{1} S\right)$ production sources from coordinated rocket and satellite measurements. $J$. geophys. Res. 84, 5345 .

Sharp, W. E., Rees, M. H. and Stewart, A. I. (1979) Coordinated rocket and satellite measurements of an auroral event: 2 . The rocket observations and analysis. $J$.geophys. Res. 84, 1977.

Slanger, T. G. and Black, G. (1981) Quenching of $\mathrm{O}($ 'S) by $\mathrm{O}_{2}\left(\mathrm{a}^{\mathrm{l}} \Delta_{\mathrm{g}}\right)$. Geophys. Res. Lett. 8, 535.

Solheim, B. H. and Llewellyn, E. J. (1979) An indirect mechanism for the production of $\mathrm{O}\left({ }^{1} \mathrm{~S}\right)$ in the aurora. Planet. Space Sci. 27, 473.

Solomon, S. C., Hays, P. B. and Abreu, V. J. (1988) The Auroral $6300 \AA$ emission : observations and modelling. $J$. geophys. Res. 93, 9867 .

Stamnes, K. (1980) Analytical approach to auroral electron transport and energy degradation. Planet. Space Sci. 28 , 427.

Stamnes, K. (1981) On the two-stream approach to electron transport and thermalization. J. geophys. Res. 86, 2405.

Strickland, D. J., Book, D. L., Coffey, T. P. and Fedder, J. A. (1976) Transport equation techniques for the deposition of auroral electrons. J. geophys. Res. 81, 2755.

Strickland, D. J., Jasperse, J. R. and Whalen, J. A. (1983) Dependence of auroral FUV; emissions on the incident electron spectrum and neutral atmosphere. $J$. geophys. Res. 88, 80511.

Strickland, D. J., Meier, R. R., Hecht, J. H. and Christensen, A. B. (1989) Deducing composition and incident electron spectra from ground-based optical measurements: Theory and model results. J. geophys. Res. 94, 13527.

Tarasova, T. M., Yagodkina, O. I., Bogdanov, N. N., Yevlashin, L. S., Mikirov, A. E. and Shidlovski, A. A. (1981) Height profile of polar aurora in the red and visible regions of the spectra according to measurements from FranzJoseph Land. Results of Researches on the International Geophysical Projects. Aurora Airglow 28, 44 .
Thomas, R. J. and Donahue, T. M. (1972) Analysis of Ogo 6 observations of the OI $5577-\AA$ tropical nightglow. Planet. Space Sci. 77, 3557 .

Vallance Jones, A. (1974) Aurora. D. Reidel, Dordrecht, Holland.

Vallance Jones, A. (1975) A model for the excitation of electron aurora and some applications. Can. J. Phys. 53, 2267.

Vallance Jones, A. and Gattinger, R. L. (1981) TV morphology of some episodes of pulsating aurora. Can. J. Phys. 59, 1077.

Vallance Jones, A., Creutzberg, F., Gattinger, R. L. and Harris, F. R. (1982) Auroral studies with chain of meridian-scanning photometers-1. Observations of proton and electron aurora in magnetospheric substorms. $J$. geophys. Res. 87, 4489.

Vallance Jones, A., Gattinger, R. L., Shih, P., Meriwether, J. W., Wickwar, V. B. and Kelly, J. (1987) Optical and radar characterization of a short-lived auroral event at high latitude. J. geophys. Res. 92, 4575.

Vallance Jones, A., Meier, R. R. and Shefov, N. N. (1985) Atmospheric quantal emissions : a review of recent results. J. atmos. terr. Phys. 47, 623.

Van Zyl, B., Gealy, M. W. and Neumann, H. (1984) Prediction of photon yields for proton aurorae in an $\mathrm{N}_{2}$ atmosphere. J.geophys. Res. 89, 1701.

Velichko, V. A., Samsonov, V. P. and Nadubovich, Ya. A. (1981) Vertical and horizontal profiles of the surface brightness of discrete aurora forms in $4278 \AA$ and $6300 \AA$ emissions. Results of Researches on the International Geophysical Projects. Aurora Airglow 28, 27.

Wasser, B. and Donahue, T. M. (1979) Atomic oxygen between 80 and $120 \mathrm{~km}$ : evidence for a latitudinal variation in vertical transport near the mesopause. $J$. geophys. Res. 84, 1297.

Wickwar, V. B., Baron, M. J. and Sears, R. D. (1975) Auroral energy input from encrgetic clectrons and Joule heating at Chatanika. J. geophys. Res. 80, 4364.

Yagodkina, O. I., Bogdanov, N. N., Tarasova, T. M., Orlovla, M. V., Mikirov, A. E. and Kachekan, V. A. (1981) Height distribution of emissions of aurora in the near-I.R. region. Results of Researches on the International Geophysical Projects. Aurora Airglow 28, 47.

Yau, A. W. and Shepherd, G. G. (1979) Energy transfer from excited $\mathrm{N}_{2}$ and $\mathrm{O}_{2}$ as a source of $\mathrm{O}\left({ }^{1} \mathrm{~S}\right)$ in the aurora. Planet. Space Sci. 27, 481 . 